\title{
WestVirginiaUniversity
}

THE RESEARCH REPOSITORY @ WVU

Graduate Theses, Dissertations, and Problem Reports

2014

\section{Tides and Air}

Kristine R. Synowka

West Virginia University

Follow this and additional works at: https://researchrepository.wvu.edu/etd

\section{Recommended Citation}

Synowka, Kristine R., "Tides and Air" (2014). Graduate Theses, Dissertations, and Problem Reports. 377. https://researchrepository.wvu.edu/etd/377

This Thesis is protected by copyright and/or related rights. It has been brought to you by the The Research Repository @ WVU with permission from the rights-holder(s). You are free to use this Thesis in any way that is permitted by the copyright and related rights legislation that applies to your use. For other uses you must obtain permission from the rights-holder(s) directly, unless additional rights are indicated by a Creative Commons license in the record and/ or on the work itself. This Thesis has been accepted for inclusion in WVU Graduate Theses, Dissertations, and Problem Reports collection by an authorized administrator of The Research Repository @ WVU. For more information, please contact researchrepository@mail.wvu.edu. 


\title{
Tides and Air
}

\author{
Kristine R. Synowka \\ Thesis submitted to the \\ College of Creative Arts \\ At West Virginia University \\ in partial fulfillment of the requirements \\ for the degree of \\ Master of Fine Arts \\ in \\ Intermedia \\ Gerald Habarth, M.F.A., Committee Chair \\ Michael Sherwin, M.F.A. \\ Dylan Collins, M.F.A. \\ Joe Galbreath, M.F.A.
}

School of Art and Design

\author{
Morgantown, West Virginia
}

2014

Keywords: Intermedia, Animation, Sculpture, Interactivity, Comics Copyright 2014 Kristine R. Synowka 


\section{Abstract \\ Tides and Air \\ by Kristine R. Synowka}

This thesis discusses the intermedia and sculptural artwork for Kristine R. Synowka's exhibition, Tides and Air. Through a wide variety of different media, both traditional and electronic, a hypothetical world split between terrestrial plants and weeds and ocean environments is explored within the space of the gallery. Echoing the movement of the viewer through the gallery space, the imagery switches focus from the familiar backyard plants to an oceanic realm based off the kinds of environments that we mostly know from theory. A possible new mythology relating to animals is subtly hinted at through encounters with artwork portraying animals from my own personal set of symbols. The ultimate myth or narrative suggested by the work is left for the viewer to form for his or herself. 


\section{Acknowledgments}

First and foremost, I would like to thank the entire faculty and community of graduate and undergraduate students here at West Virginia University. I am grateful to have had the opportunity to earn my MFA in such a supporting and dynamic environment. I am especially appreciative of the consideration, time, and advice given to me by my graduate committee: Gerald Habarth, Michael Sherwin, Dylan Collins, and Joseph Galbreath, without whose support this exhibition would not be possible. I must enthusiastically thank Rafael Laguni Smith for composing the fantastic music for the interactive piece in the exhibition. A special thanks must also go out to my supporting family and friends, as well as to Erika Osborne, who served on my committee during her time teaching at West Virginia University. 


\section{Table of Contents}

Abstract..........................................................ii

Acknowledgments...........................................................ii

Table of Contents..................................................iv

Introduction............................................................

Chapter 1: The Question of Mythology......................................1

Chapter 2: Air and Sea, the Layered World........................................ 3

Chapter 3: Encounter.................................................

Conclusion.......................................................................... 14

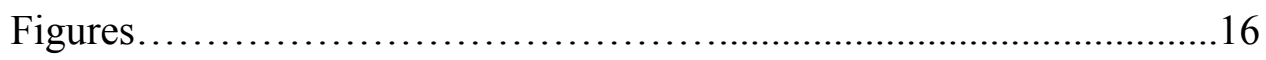

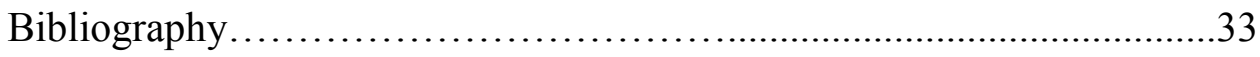




\section{Introduction}

In the past, cultures connected to their environments and the various species that inhabit them through myths and legends. Mythological imagery and folklore formed the interface for interactions with animals and ecosystems. Today, our cultural media presents a confused and conflicted way of looking at the natural world. This body of work poses a potential direction for a new mythology of the natural world by hybridizing old animal gods and environments with imagery from video games, comic books, biology, and animation.

Shifting the frame of reference of the viewer onto close up imagery of backyard wildflowers and weeds, a reorganized perspective of that biological world is blended with imagery from oceans and tide pools - environments that are much more difficult for human beings to become familiar with. These chimerical ecosystems suggest at a hypothetical narrative world, at the edge of knowledge and experience, that exists alongside and overlapping our own.

I have portrayed this world and its denizens by laborious handmade sculptures, animations, and meticulous drawings. By keeping a handmade aesthetic central to the appearance of my work, I emphasize it as an act of personal exploration - in contrast to the way that associations of consumerism are attached to video games and animation in pop culture. A handmade aesthetic also poignantly speaks to the unconscious desire of the viewer to create.

Within this world suggested at by the work within the gallery space, and very much inseparable from both their biological, mythological, and pop cultural heritage, the viewer encounters its denizens. These are temporarily quiescent leviathan-gods and devious animal tricksters from the old stories. Yet, the animal figures represented by this work are renewed and decontextualized creatures stepping out of the past. The final narrative of the encounter and the new roles of these creatures can only be completed in the experience of the viewer.

\section{Chapter 1: The Question of Mythology}

An innocent and enthusiastic fascination with biology, comic books, animation, video games, and contemporary literature form the driving force behind my work. These diverse 
elements merge together within the work to form subtle narratives. The images that I create from this source material resonate deeply with me and quite possibly could be considered a personal, internal mythology. However, the work I create, is not primarily concerned with being an act of self-exploration - what occurs in the mind of the viewer as a reaction to my imagery is of urgent importance. Prompted by a deep concern for the way our culture interacts with nature, I aim to create a space for the viewer to reassess how they internally regard the natural world.

Recent studies comparing literature and the theory of evolution suggest that our shared biological heritage shapes the drive to tell narratives and that storytelling has important social functions. ${ }^{1}$ Likely very few people would argue even without scientific evidence that people have an innate need to tell and listen to stories. Neil Gaiman, a fiction writer, articulated this matter in a particularly powerful way in his novel, Anansi Boys: "People respond to the stories. They tell them themselves. The stories spread, and as people tell them, the stories change the tellers...now they're starting to dream about a whole new place to live. The world may be the same, but the wallpaper's changed." 2 The effects of a story can continue going on in the background of a person's life. This idea became a keystone idea for me.

Along these same lines of thought, the writings of Joseph Campbell are also very important to the development of my work. The idea that myth is an archetypical story that takes on the symbolic shapes of whichever culture is doing the telling is a powerful idea in and of itself. $^{3}$ However, Campbell also suggested that human beings have a profound, psychological need for a guiding set of mythological symbols in order to make sense of our subconscious selves, and that the lack of mythology in a prominent role in our culture today corresponds to a rise in neuroticism. ${ }^{4}$ In an interview between Campbell and the journalist, Bill Moyers, when asked about what happens in a society where mythology no longer plays an important role, Campbell replied, "...read the New York Times." ${ }^{5}$ On a more optimistic note, and of great importance to my ideas, Campbell also notes that psychoanalysis provides evidence that without

1 Priya Shetty, "Novels act like social glue, say literary Darwinists," New Scientist, 201, no. 2691 (January 17, 2009): 10. Academic Search Alumni Edition, EBSCOhost (accessed April 12, 2014).

2 Neil Gaiman, Anansi Boys (New York: Harper Torch, an Imprint of HarperCollins Publishers, 2005), 291.

3 Joseph Campbell, The Hero with a Thousand Faces (2nd. ed. Princeton: Princeton University Press, 1949), 3-4.

4 Ibid., 11.

5 Joseph Campbell, with Bill Moyers, The Power of Myth, edited by Betty Sue Flowers (New York: Doubleday, a Division of Bantam Doubleday Dell Publishing Group, 1998), 8. 
a guiding "general mythology", people will cultivate their own tapestry of personal symbols. ${ }^{6}$

This is the starting point from where I make work: the idea that people, having the need for narratives and mythology, will automatically start to form their own - even if they are not aware of it. One point that must be articulated clearly though, is that one brief experience in a gallery cannot plant an entire pantheon of myth directly into the mind of the viewer, and in no way do I claim to do so in this exhibition. The power in this work is of invitation and suggestion. My animations, drawings, and sculptures are born from my own personal mythology. However, they are presented to the viewer in a manner that just hints at how these elements might come together. This leaves plenty of room for the viewer to explore and find his or her own meanings behind the imagery. The most exciting prospect in the work for me, is what hypothetical directions these symbols will take in the narrative that is quietly going on in the background of the viewer's life. Looking further into the presentation and specific artworks of the exhibition, Tides and Air, sheds light on how the symbols and imagery I use encourage positive interaction with these ideas.

\section{Chapter 2: Air and Sea, the Layered World}

The exhibition, Tides and Air, consists of multiple animations of landscapes, an interactive piece reflecting on the experience of flight, an elaborate wall painting, and culminates in the encounter of a twenty-foot long sculpture of a shark. For now, I will focus on the use of landscapes and plants and their role in creating the setting and environment in which the hypothetical narrative takes place.

One of the first pieces in the exhibition, located at the entrance of the gallery was the animation, Breath of Clovers (fig. 1). Displayed on a flat-screen television, the animation consisted of an extreme close up of many tiny weeds blowing in the wind. While the animation itself ran on a short, but simple loop, the multitude of animated plants and the rich variety of greens of the foliage gave the piece a strange, complex hypnotic quality. This animation was the first of three, which were all handled similarly. The other two, Breath of Tides (fig. 2) and

6 Joseph Campbell, The Hero with a Thousand Faces, 4. 
Ocean Currents (fig. 3), ran alternatively on a large projector in the main area of the gallery near the sculpture of the shark. Both of these were handled in a similar manner to Breath of Clovers, although they ran on longer loops and were more intricate. All three animations focus on closeups of vegetation undulating either in wind or under water, although Ocean Currents also included various species of Caribbean fish darting in and out of the underwater flora. The plants themselves were drawn in black and white and then scanned into the computer, where the linework was colored. Additionally, textures created from watercolor paintings were added to the plants to increase the handmade appearance of the work. Backgrounds were hand painted and also scanned in. Once all the pieces were completed (plants, backgrounds, and any water or lighting effects), they were imported into Adobe After Effects for animation. The resulting animations had a strong hand-made look to them, despite the fact that at least fifty percent of the work owed itself entirely to the computer.

At first glance, these pieces seem to have very little to do with mythology, but everything to do with commercial animation and video games. Strong visual ties to sprite-based sidescrolling games are present in the strategic and aesthetic use of cloning the assets used in the animations. Video games of any era all face the task of creating enormous worlds with only a limited amount of storage space, and therefore the use of repeating elements to create imagery was a necessity. For example, the maximum size that could be stored on an old Sega Genesis cartridge was no more than 5 megabytes of data. ${ }^{7}$ Game developers and artists worked with these limitations and created appealing imagery based on repetition, as seen in this screen capture from the game Sonic and Knuckles (fig. 4). Repetition as an aesthetic decision is a concept I have embraced. For example, in Breath of Clovers and Breath of Tides all of the animated clovers originate from a set of six drawings, whose size and color are then manipulated in the computer. The plants of these animations are outlined in bold contour lines typical of hand-animated two-dimensional animation, and the technique of coloring the drawings with a painted texture was inspired by the movie, The Secret of Kells (fig. 5). ${ }^{8}$ This film also uses a great deal of repeated animated assets in its aesthetics as well. My decision to focus on close ups

7 “Sega Genesis," TV Tropes Foundation, http://tvtropes.org/pmwiki/pmwiki.php/Main/SegaGenesis (April 13, 2014).

8 Tomm Moore, The Secret of Kells, DVD, directed by Tomm Moore, Nora Twomey (2008; New Video Group, Inc, 2010). 
of tiny plants moving in the wind was also directly inspired by the opening scene of the movie Kiki's Delivery Service, which featured a painstakingly hand animated field of weeds and grasses blowing in the wind (fig.6). ${ }^{9}$ I perceive my animations as having a similar function to the concept of the establishing shot in cinema. Just as the animated plants at the beginning of Kiki's Delivery Service drew the viewer into the atmosphere of the narrative, so do my animated sequences draw the viewer into the my world of hypothetical myth.

A small interactive piece, titled The Experience of Flight (fig. 7), also shared these visual influences. This piece functioned as an intermediary work between the animated environments and the animal-based artwork included in the exhibition. The viewer controlled a raven character that explored another slice of the same world that was suggested at in the other animations. However, here the perspective of the camera was significantly zoomed out. The environment in The Experience of Flight put the other animations into perspective. Here was a slice of the world in the form of a wooded area at the water's edge with wildflowers blowing in the wind. The context of the placement of these pieces within the gallery started to take on a narrative as well. With Breath of Clovers at the entrance, the viewer passed it and descended down the spiraling ramp towards the main area of the gallery. At the foyer near the base of the ramp was The Experience of Flight, in which the viewer interacted with the raven to either fly into the treetops, or to walk around where the waves meet the land. Continuing the remaining distance down the ramp to the main area of the gallery, Breath of Tides and Ocean Currents shared a projector. The two pieces alternated back and forth, projected huge on the wall. Breath of Tides showed an impossible close up of the tide line where the water sharply divides terrestrial plants and tide pool algae. Ocean Currents was fully submersed underwater. The viewer essentially spends his or her time in the gallery surrounded with imagery of either ascending or descending.

Just what is the world implied by these detailed animations of terrestrial plants and aquatic algae and why shift the viewer's focus between land and sea? The first clue lies in the types of terrestrial plants selected for the animations. Every single terrestrial plant in Breath of Clovers and Breath of Tides is a real species that I have personally identified as a common weed or wildflower in the northeastern half of the United States (although, admittedly, I was much less

9 Hayao Miyazaki, Kiki's Delivery Service, DVD, directed by Hayao Miyazaki (1989; Burbank, CA: Buena Vista Home Entertainment, 2003). 
picky about the grasses). Since Tides and Air was being exhibited in West Virginia, I could expect some familiarity with the appearance of these weeds. Even the viewer least likely to recognize a plant from his or her backyard would recognize clover. This plant is easily identifiable due to both the superstition involving the four-leaved variety and the fact that this plant is so widespread in many lawns. Clover is present in or on every piece in the exhibition. The use of backyard weeds and wildflowers in my imagery is, therefore, used to signify places and elements of the natural world that we are familiar with in our daily lives - the part of nature that the viewer will be directly familiar with. Oceanic and tide pool flora and fauna then logically represent the opposite - environments that are not directly experienced with great familiarity by the viewer. This is the territory where the unknown stares out from the gap between experience and second-hand knowledge. This imagery forms a loose association between the diametric opposites of down and up, the aquatic and the terrestrial...between tides and air.

This decision to combine the movement of the viewer through a space with narrative and symbol is partially influenced by Matthew Barney's Cremaster Cycle (fig. 8), which is named for the muscle that raises and lowers the testicles. Indebted to Barney's influences from performance art and his experiences as an athlete, the movements of the human itself become part of the language Barney uses in his films. ${ }^{10}$ Characters in the Cremaster Cycle are constantly crawling, climbing, and engaged in other various physical activities as they act out Barney's highly personal world of symbol. ${ }^{11}$ In Cremaster 3, these narrative movements even take place at the Guggenheim Museum ${ }^{12}$ - a gallery space.

Also important to my decision to use multiple pieces in Tides and Air in order to establish a setting, is the idea that worlds can overlap and co-exist within the same space. This is an idea that I adopted from two contemporary fantasy novels, Neil Gaiman's Neverwhere and Gabriel King's The Wild Road. In Neverwhere, the protagonist Richard loses his place in contemporary London - "London Above" - and falls into a second parallel London called "London Below" or

10 Ben Lewis, "Matthew Barney," Art Safari, DVD, directed by Ben Lewis (2002-05; Icarus Films Home Video, 2009).

11 Ibid.

12 Ibid. 
the "Underside", which is "inhabited by the people who fell through the cracks in the world."13 This alternative London exists side by side with the familiar one, yet once fallen into "London Below", Richard finds that people from "London Above" act as though they no longer see him and it is as though he has been completely erased from his old life. ${ }^{14}$ The Wild Road, on the other hand, weaves a story about the world from the perspectives of feral cats and urban wildife. In this tale, animals create abnormal areas of space called "highways" by repeated travel over specific paths over the course of their lifetimes. ${ }^{15}$ The descriptions of the "highways" in this novel especially lent themselves to the evolution of the idea to consider my hypothetical narratives as existing on another layer of our world. When the protagonists entered a "highway" for the first time and had to struggle to get his bearings, King wrote, “...the problem, perhaps, was that they were somehow too dense - as if a hundred houses occupied the space of house, a thousand trees the space of one tree..."16 This text brought to life a landscape that was made up of hundreds of overlapping layers of landscapes all occupying the same three dimensional coordinates.

Both of these novels construct narrative spaces involving worlds that come together and share the same physical space in novel and unusual ways. While greatly removed from its source of inspiration, the artwork in the exhibition hints at a world that shares the same physical space as the gallery. This is not quite the same as transforming the gallery into an installation space. Instead of immersion, the goal is dialogue with the unconscious part of the viewer that is perpetually shaping pieces of narratives from the imagery and symbols the viewer encounters. It is left to the viewer to decide how that environment links together. The animations of plants and landscapes within the exhibition set up this dynamic, but, as will be seen in the next segment, it is the imagery of the animal that activates it.

\section{Chapter 3: Encounter}

That the viewer sees the landscapes in relation to the cast of animal characters that form

13 Neil Gaiman, Neverwhere (New York: Harper Perennial, an Imprint of HarperCollins Publishers, 1996), 127. 14 Ibid., 86.

15 Gabriel King, The Wild Road (New York: Del Rey, an Imprint of Ballantine Publishing Group, 1997), 138-139. 16 Gabriel King, The Wild Road, 143. 
the core of my personal mythology was essential, and these two components come together by way of the idea of an encounter. Most of our direct experiences with animals take this form look out the window at the right time on a late summer evening and perhaps a doe will be foraging on fallen apples in the yard, or there will be a brief flash of color as a songbird takes dipping drinks from a pothole on the street after the rain. Brief, vibrant, and unexpected, encounters with wildlife weave in and out of our lives. In my personal case, encounters with animals lead to a more intense recollection of the details in the background and my eyes are drawn just as much to the texture of the asphalt and the reflections of power lines in the water as I am to the bird itself. For a few split seconds, my attention is solely on the bird's world. This mode of thought was very important to how I perceived Tides and Air working together as a whole.

Returning to the entrance to the exhibition, the other piece that greeted the viewer, in addition to Breath of Clovers was an untitled wall mural of a fox, a magpie, and a white raven clustered around a rotted stump with ever-present clovers and plantain weeds growing in the surrounding field (fig 9). These figures are straight out of my regular pantheon of beasts and carry artifacts from older narratives with them. The bell around the raven's neck and the garden on the fox's back were elements from my previous fiction writing. No explanation is offered, though in case of the garden, it blurs the border between the animal and its environment. The raven's bell remains a mystery, but there is power in its meaning remaining closed to the viewer. All three creatures also have some significance in mythology or folklore. This is especially true of the raven, which finds representation in the myths and legends of many cultures - ranging from tribes in the Pacific Northwest who saw the Raven as both creator-god and trickster to the practice of keeping ravens in the Tower of London to supposedly prevent the fall of England. ${ }^{17}$ However, while each of these animals has a history outside of my personal mythology, I present my characters in an ambiguous new context for the viewer to ponder.

The mural provides the strongest link to my inner mythology out of any piece in the exhibit. The decision to focus on vaguely cartoonlike animals hand-painted with intricate line work and limited shading using metallic paint was strongly inspired by the work of Kumi

17 John M. Marzluff and Tony Angell, In the Company of Crows and Ravens (New Haven, CT: Yale University Press, 2005), 111-112. 
Machida, a Japanese artist whose strange figures of people communicate a highly personal set of symbols based off her own doubts, fears, and memories. ${ }^{18}$ Machida's visual language is incredibly rich. However I was also drawn to her work because I discovered it while I was questioning how essential it was for the viewer to be able to take a clear and distinct reading away from my own. I was fascinated that I could not completely decode her paintings. Nor do I think the viewer is meant to. For example, in the piece, La Degrange (fig. 10), I can see that the figure is wearing a strange helmet that is locked to his or her head at the throat and that the pressure is building up inside that helmet to the bursting point. The emotional tension in the piece is unmistakable, but there is a strong sense of being limited as to how far into Machida's private world of symbols I can go. The uncomfortable tension in the imagery combined with the specificity of her characters accounts for part of this effect, but the medium also strongly enhances the private feeling of her paintings. Machida's technique and choice of medium in relation to her subject matter had a compelling resonance with my own handmade aesthetics. Her figures are modern entities; with crisp, clean line work reminiscent of illustrations, vector art, or possibly Manga. Yet, these paintings are made with the exacting techniques of traditional nihonga painting, with ink or powdered pigments, on kumohadamashi paper, which posses a distinct texture that resembles canvas. ${ }^{19}$ The process is so demanding that, as Machida paints, she wears a mouthpiece to protect her jaw from the pressure of gritting her teeth. ${ }^{20}$ Evidence of personal labor becomes evidence of the person who created the piece. Were these images massproduced from vector-based artwork, this would take the work in a direction away from the aura of privacy that is essential to the power of the artwork.

I have used medium as a way of redirecting the commercial associations of the pop culture influences in my practice for a long time. This possibility was first brought to my attention through the paintings of Yoshitomo Nara. While Nara is obviously influenced by Japanese animation and Manga, his work is painted in subtle desaturated shades of acrylics, instead of the bright colors of most commercial art. ${ }^{21}$ Especially apparent in his painting, Sprout the Ambassador (fig. 11), are the subtle hand painted variations of the solid colors in the girl's

18 David Elliot and Tetsuya Ozaki, Bye Bye Kitty: Beyond Heaven and Hell in Contemporary Japanese Art (New York: Japan Society, 2011), 33-34.

19 Yumi Yama, Warriors of Art, translated by Arthur Tanaka (Tokyo: Kodansha International, 2007), 68.

20 Ibid., 68.

21 Valerie Breuvart, ed., Vitamin P (London: Phaidon Press Limited, 2002), 232. 
dress and the faint shadows on her body. Nara's work both explores the solitude of his childhood and the fleeting act of both empathizing with and wondering at the thoughts behind the characters that stare out from the paintings. ${ }^{22}$ The handmade quality of these paintings focuses the commercialized influences of the work through the lens of Nara's experience. My work may be more concerned with creating a space in which the viewer can explore a hypothetical animalbased mythology than relaying my own personal narratives, however, as this work is intended to speak to the viewer's own creativity, I find that a strong hand-made aesthetic serves this purpose well.

That Nara's characters also stare out from their canvases with such powerful gazes has also played a significant role in my choice to anthropomorphize the animal characters both in the wall mural and in The Experience of Flight. I have long been fascinated by the question of how animals perceive the world with their alien senses and the question of animal consciousness and cognition. For a long time, I have kept up with the current research that is being conducted to evaluate these questions. Animals are very alien from us; even familiar ones that we share our lives with, and we have many misconceptions about them. For example, new research has shown that cats and dogs can see ultraviolet light, which is outside the usual spectrum of visible light in humans. ${ }^{23}$ This is a far cry from the old myth that cats and dogs see in black and white. The similarities are just as noteworthy. One of the most important statements in regards to animals occurred on July 7, 2012 and is known as the Cambridge Declaration on Consciousness. ${ }^{24}$ A group of renowned experts of various fields within the neurosciences met to publicly acknowledge that, after looking at various studies of the areas within the brain that correlate with consciousness, "non-human animals, including all mammals and birds, and many other creatures, including octopuses, also possess these neurological substrates." 25 The subtle, anthropomorphic qualities I gave to many of the animal-based images in the show were meant to

22 Valerie Breuvart, Vitamin P, 232.

23 Jennifer Viegas, "Cats Have Super, Psychedelic Vision,” Discovery Communications, LLC, last modified February 18, 2014, http://news.discovery.com/animals/pets/cats-have-super-psychedelic-vision-14028.htm (accessed April, 22, 2014).

24 Phillip Low, “Cambridge Declaration of Consciousness," edited by Jaak Panksepp et al. (paper presented at the Francis Crick Memorial Conference on Consciousness in Human and non-Human Animals, Cambridge, UK, July 7, 2012, http://fcmconference.org/img/CambridgeDeclarationOnConsciousness.pdf, accessed April 23, 2014).

25 Ibid. 
suggest to the viewer that my characters are conscious entities. However, there is an intended level of ambiguity in their expressions that celebrates what we do not and cannot ever know about their minds and perceptions. For an animal-based mythology to be relevant to our times, the mystery of animal consciousness must on some level be recognized.

The next encounter of the exhibition was the previously mentioned, The Experience of Flight. While the role of its landscape in establishing context has already been discussed, it must be reexamined for the interactive attributes, which make it unique among all of the other work in the exhibition. The set up was simple (fig. 12); a large flat screen television was set on top of a pedestal that concealed the computer that was used to run the program. An old Sega Genesis game controller was used for the interface, and when, not in use, hung from a hook on the pedestal. No instructions or explanations of any kind were given. The area in which the viewer could explore within the program was small and the environment was two dimensional - taking the exact format as a two dimensional side-scrolling video game, like the previously mentioned Sonic and Knuckles. The interactive piece also played soft, ambient music with wave sound effects included in the composition that was created specifically for the exhibition. This music extended into the gallery and also helped to loosely unite the pieces within the space.

The main focus on the interactive piece was to allow the viewer to focus on learning to fly the bird. Written directions would have been intrusive to the experience, and therefore the piece relies heavily on pre-established gaming conventions that would already be familiar to a large portion of the audience. ${ }^{26}$ For viewers without that strong sense of familiarity, controls were kept very simple. The choice of using an old school game controller also aided in this, as this type of controller has a much more limited amount of buttons compared to newer models.

In gaming, the usual convention is to see the controlled character as an avatar for the person playing the game. However, with nothing to do but to focus on the process of flight in a small area that allows little along the lines of exploration combined with just the oddness doing this task in a gallery, I would suggest that the viewer never fully accepts the bird as an extension of himself or herself. Instead, it is the beauty of flight that is brought into focus and a certain feeling of bodily empathy with the movements of the bird.

26 Mark J. P. Wolf, “Assessing Interactivity in Video Game Design,” in Mechademia 1: Emerging Worlds of Anime and Manga, edited by Frenchy Lunning (Minneapolis, University of Minnesota Press, 2006), 80. 
As mentioned before, the idea of the viewer being able to relate the exhibit to their own body had been a subtle thread throughout Tides and Air. Nowhere was this idea more important than with the untitled great white shark sculpture (fig. 13). Due to its sheer size and the way the gallery space leads to it, this piece was the focus of the entire exhibition. At twenty feet long, the sculpture was the size of large specimens of its real life counterpart ${ }^{27}$, and clearly dwarfs the viewer. The viewer physically encountered the immense sculpture after seeing the other work that established a context for the piece, and after physically descending down the gallery's ramp. The shark itself was facing away from the viewer with the curve of its tail echoing the architecture of the ramp. It hung suspended from the ceiling by nearly invisible cables at eye level. By forcing the viewer to approach the enormous leviathan from behind, a narrative was formed to play off of some of our more primitive insecurities of predator and prey. The intention was to pose the narrative question of whether or not the shark character was aware of the viewer or not. This was a question with no clear answer. The leviathan floated quiescent in a pose that suggested powerful motion, but was frozen in the instance of the encounter.

Once in the proximity of the beast, the details of the sculpture came into the viewer's attention. Running down each of the shark's flanks were gardens of sea life and terrestrial vegetation, which echoed the landscapes and blurred the boundary between the shark and its environment (fig. 14). Deep black, light absorbent velveteen and reflective faux velvet on the shark's back contrasted with torn white paper on its belly. Its gills were filled with collaged decorative paper in shades of hot pink and red, and, once the viewer approached the head, detailed blue eyes that were sculpted and embedded in clear resin were revealed (fig. 15). I had chosen not to anthropomorphize this sculpture, and to instead trust to its scale and the lifelike effect of the eyes to give the piece a sense of life and self-agency. This final encounter was meant to be with the unknowable aspects of my hypothetical animal mythology, and anthropomorphic features would not have been an appropriate choice.

Tracing the subtle influences within the development of the shark is more challenging than doing so for the other pieces in Tides and Air, because a significant amount of my process for this sculpture was grounded in intuition. Material-wise, I knew that it needed to be obvious that the shark was made by hand, however, I selected the various papers and fabrics that cover

27 Andrea Ferrari and Antonella Ferrari, Sharks: A Firefly Guide (1st ed. Buffalo, NY: Firefly Books, 2002), 140. 
the surface mostly by intuition and impulsive exploration. If I delighted in the shine, shape, or texture of a material or object, and the way it complemented other decisions I had made for the shark, then that was my criteria for choosing it.

From a formal standpoint, however, I was very much aware that the materials composing the space of the gallery itself were part of the holistic experience of the exhibition. The dark tile of the floor, the pale gray of the rough, stone brick walls that occasionally picked up the glitter of the gallery's lighting, the white walls at the entrance - all of these elements were kept in mind as I was choosing materials. The decision to work in a mostly black and white pallet echoed the natural contrasts in value within the gallery. The rough collage on the shark's belly was meant to have kinship with the texture of the bricks. I also paid careful attention to the sheen on the fauxvelvets that I used and welcomed the use of odd glittery decorative branches for the gardens. The way these elements caught the light corresponded to both the occasional shine the viewer might peripherally notice on the tile, and the tiny light-reflective flecks on the stone bricks.

The decision to create a twenty-foot long, life size shark sculpture was strongly influenced by my new awareness of artists who create on an enormous scale in the art world. Ai Weiwei was the first artist I encountered where I finally comprehended the irreplaceable impact that large-scale art possesses on the viewer - especially when this is combined with handcrafted elements in the work. In his installation, Sunflower Seeds (fig. 16), Ai Weiwei filled the Turbine Hall of the Tate Modern with millions of realistic porcelain sunflower seeds that had been meticulously formed and hand-painted by artisans working from small workshops in China. ${ }^{28}$ This work may have a completely different intention from the dialogue I am trying to create with the viewer, but the impact from knowing that work of such a monumental scale has been handcrafted piece by tiny piece has an undeniable power to it that can only be achieved through that combination of hand and scale. Even if it is imperfect, the viewer will possess some understanding of the labor involved in such an undertaking and feel some empathy for the individual or individuals who personally created each component of the massive undertaking.

The final point worth considering for the exhibition, Tides and Air, is the choice of the great white shark itself. Keeping with my desire to have the implied narrative of the work be an

28 “The Unilever Series: Ai Weiwei: Sunflower Seeds," Tate, http://www.tate.org.uk/whats-on/tatemodern/exhibition/unilever-series-ai-weiwei-sunflower-seeds (accessed April 24, 2014). 
elusive experience between my set of personal symbols and the viewer's, the primary reason behind using the image of a great white shark was to resonate with the cultural iconography created by the popular Jaws movie franchise (fig. 17). The popularity of the films has mythologized the image of the shark as symbol of death in our culture. ${ }^{29}$ Most prominently in the art world, Damien Hirst utilized this imagery for his famous piece, The Physical Impossibility of Death in the Mind of Someone Living (fig. 18), a thirteen-foot long shark preserved in formaldehyde and suspended in a tank made of steel and glass. ${ }^{30}$ While I also find my own sculpture at odds with this piece, in terms of aesthetics and intent, it is undeniable that I am partially playing off of the imagery of the shark as a vehicle of death. This element is added to the scale of the shark to give it power.

While our culture sees the shark as a symbol of death, other cultures, particularly those in Indo-Pacific, revere the animal as a protective deity. ${ }^{31}$ Reading these stories allowed me to perceive this animal as capable of having strong dualistic qualities and led me to partially subvert the negative Western symbolism. My sculpture encouraged the viewer to find affinity in the leviathan's uncontrollable nature. The use of delightfully tactile velvet gave the viewer a desire to touch it, and I witnessed people stroking the sculpture's head and sides on multiple occasions. The mystery of the shark's gardens also pushed the reading of the piece into further ambiguity. The sculpture was growing its own garden of plant life - it was no longer just an animal, but somehow a blend of both creature and environment. The attention to details on the surface of the shark, its true-to-life size, and the play off of the popular symbol of such a potentially dangerous and powerful animal all evoked positive emotional responses in the viewer. Very likely, no one who had attended the exhibition had ever been in the water with a living great white shark, but now there was a chance to encounter and decipher the sculpture.

\section{Conclusion}

The narrative I created in the exhibition, Tides and Air, was diffuse and subtle. With imagery from my own personal mythology and great attention to constructing a detailed world, I

29 Andrea Ferrari and Antonella Ferrari, Sharks: A Firefly Guide (1st ed. Buffalo, NY: Firefly Books, 2002), 68.

30 "The Physical Impossibility of Death in the Mind of Someone Living, 1991," Damien Hirst, http://www.damienhirst.com/the-physical-impossibility-of (accessed April 26, 2014).

31 Andrea Ferrari and Antonella Ferrari, Sharks: A Firefly Guide, 70. 
gave the viewer an opportunity to explore new ways of perceiving and relating to animals and ecosystems. This was accomplished through the use of animated landscapes that slowly shifted the viewer's attention first to close-ups of familiar weeds and wildflowers undulating in the wind and then into unfamiliar seascapes. The space of the gallery was used to echo this decision. As the viewer descended, the environment transitioned to unfamiliar territory. While stopping short of being an installation, the exhibition, nevertheless, suggested another world overlapping the space of the gallery. The obvious handmade aesthetic of the work suggested that this was to be a personal experience, despite apparent influences from commercial animation, video games and comics.

While the animations in the exhibition established a place for a hypothetical new mythology to happen, the other work portrayed animal characters that were previously species of importance in mythology and folklore. All creatures in the work were then recontextualized in ways that made their new roles ambiguous - usually by hybridizing the animal with plant-life. A fox with clover and plantain growing from its back rested in a field while ravens wearing mysterious bells around their necks soared. The viewer also encountered a life-size sculpture of a great white shark that possessed its own strange gardens growing from its sides. This vibrant imagery appealed to the curiosity of the viewer. However, instead of defining what the new roles of these animals could potentially be, the ultimate meaning was left to the imagination of the viewer. The work became an open call to participate in exploring the new mythology. 


\section{Figures}

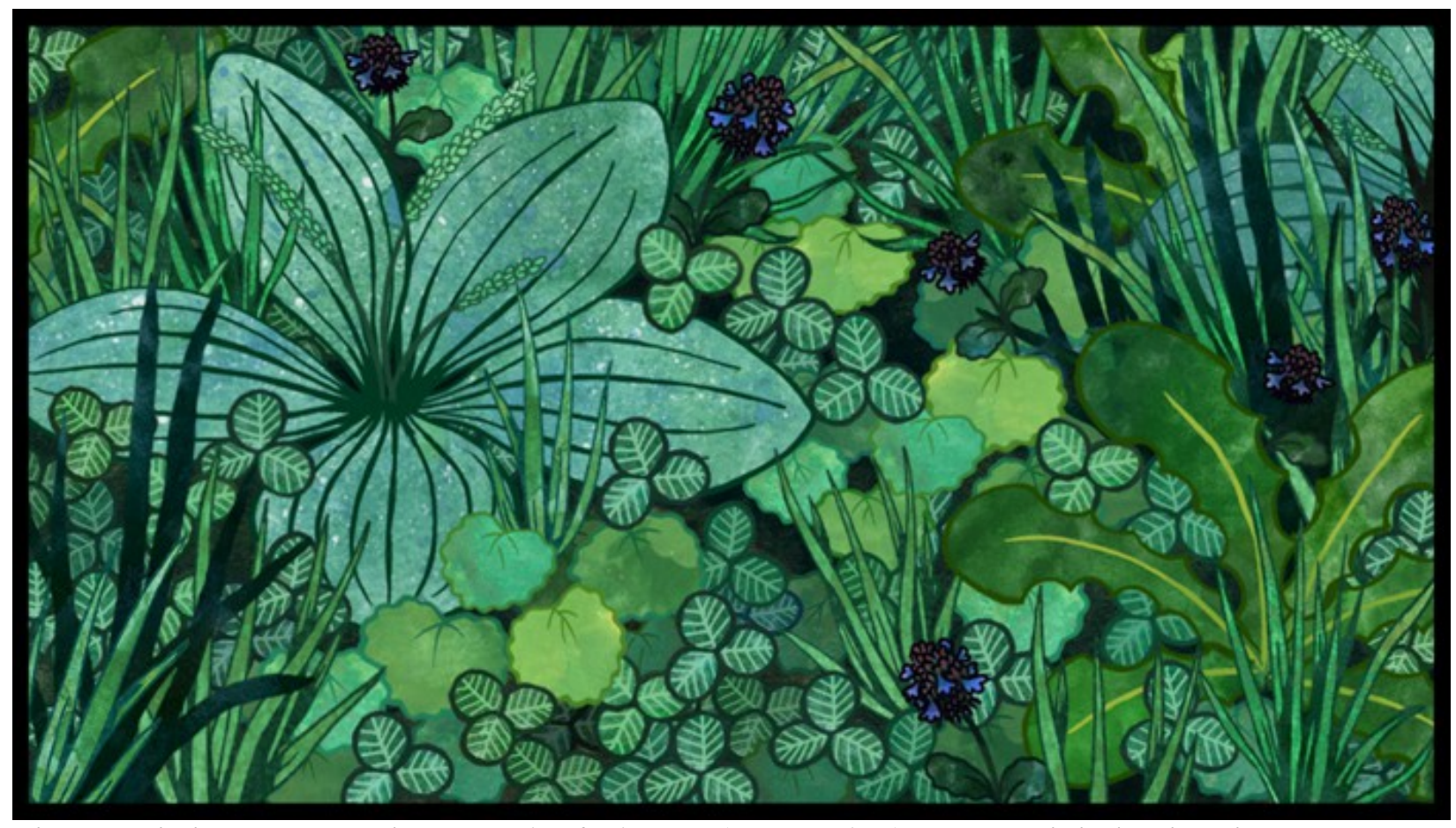

Fig. 1 Kristine R. Synowka, Breath of Clovers (screen shot), 2013. Digital animation. 


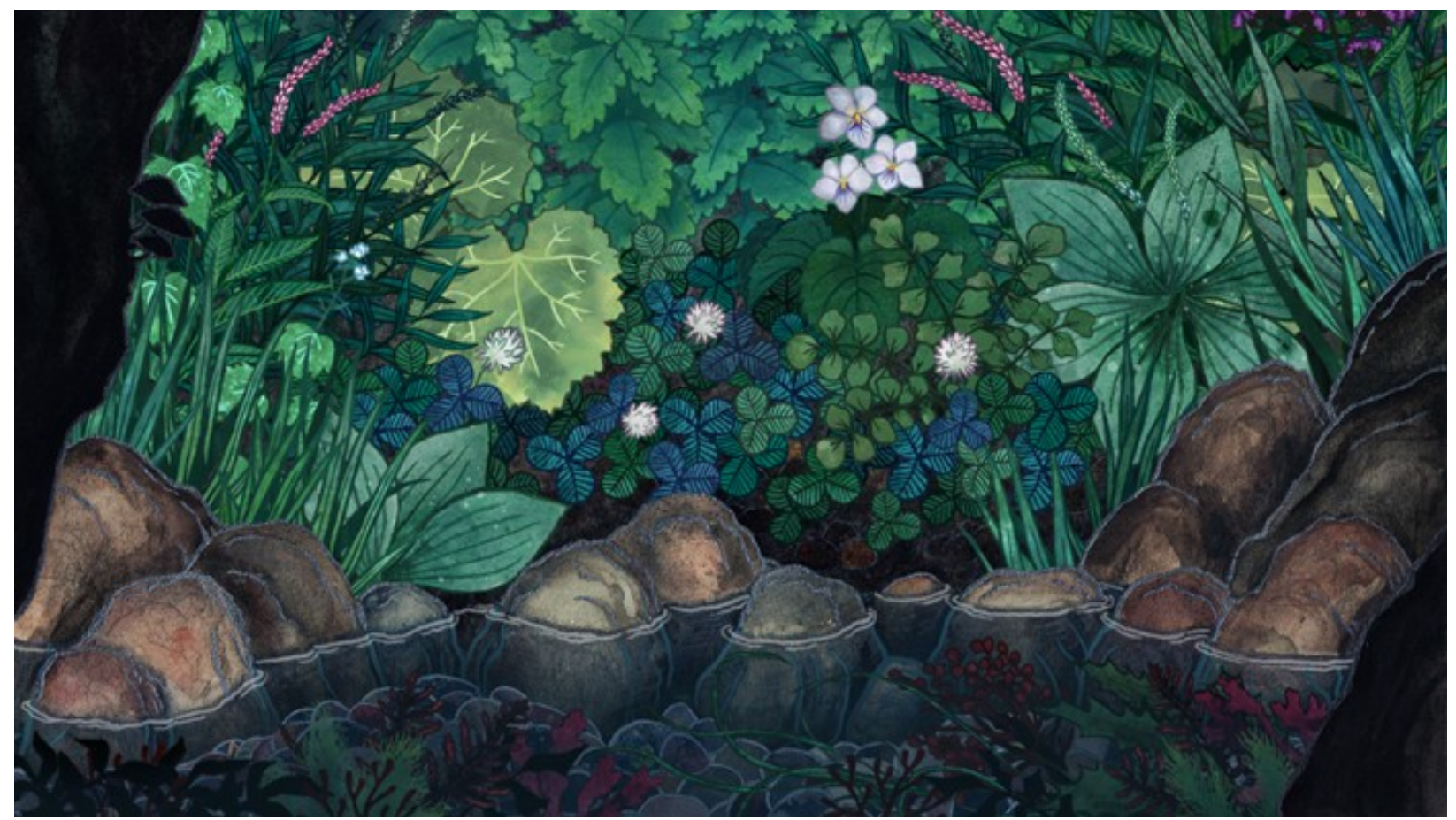

Fig. 2 Kristine R Synowka, Breath of Tides (screen shot), 2013. Digital animation. 


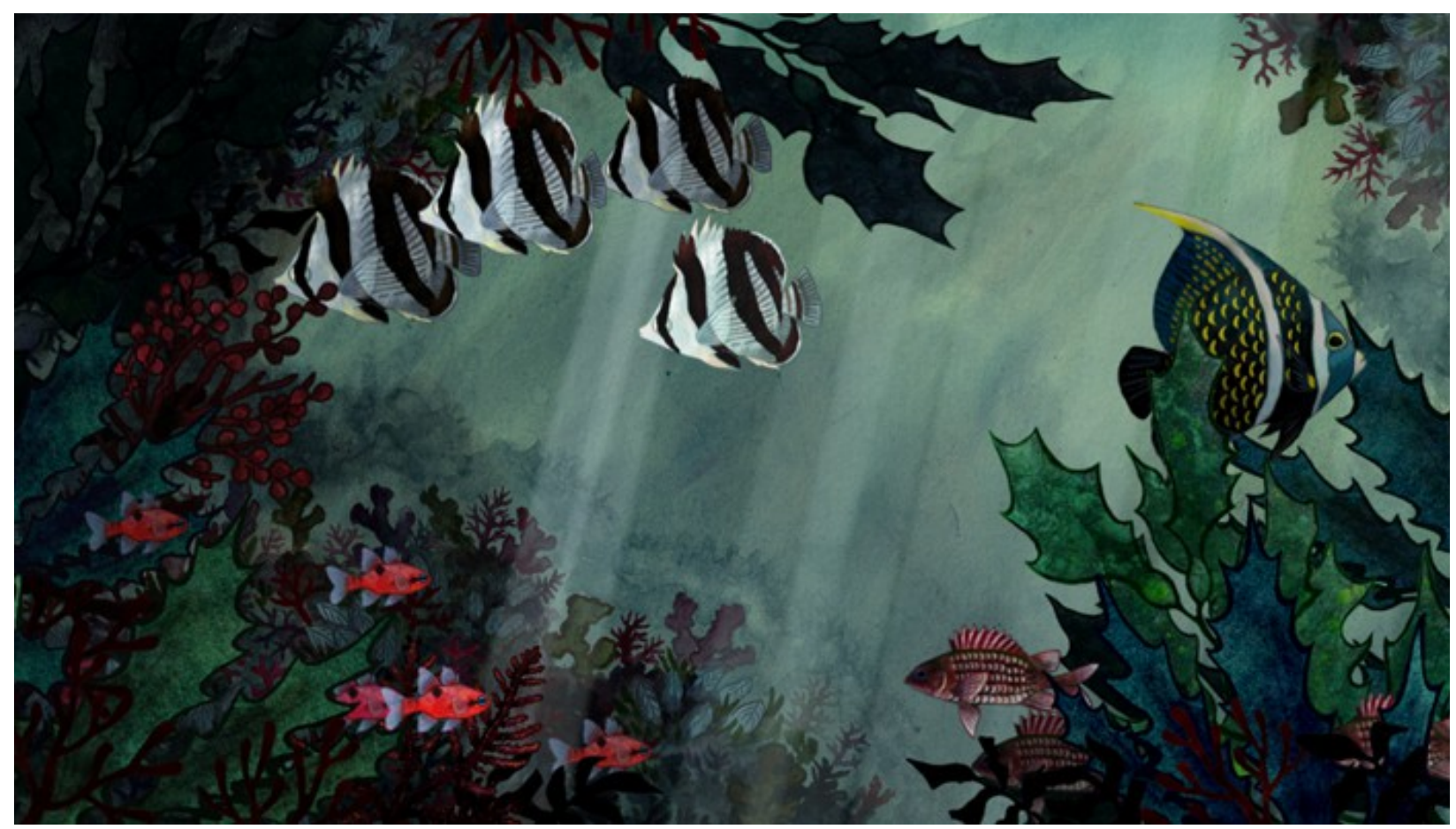

Fig. 3 Kristine R. Synowka, Ocean Currents (screen shot), 2014. Digital Animation. 


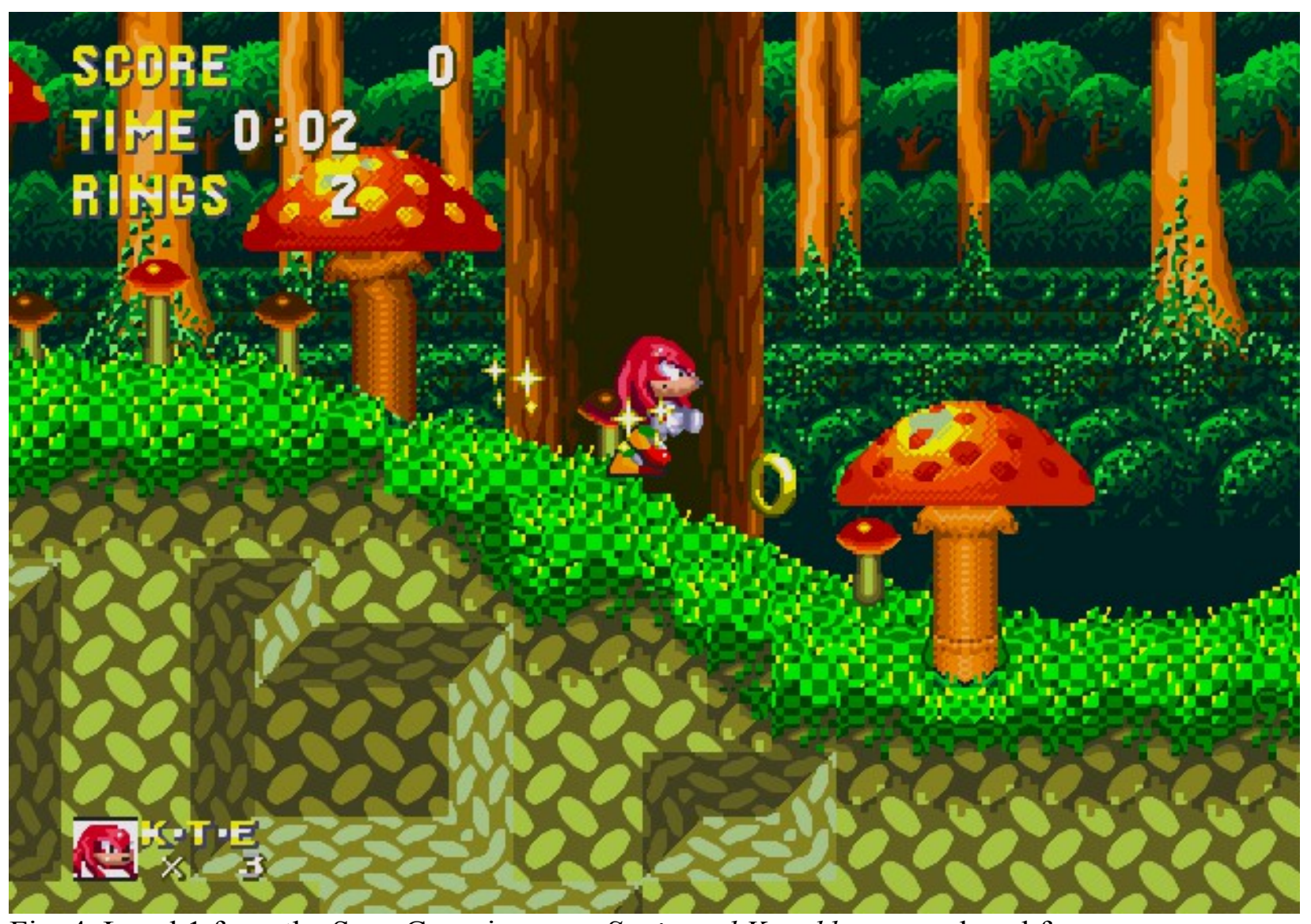

Fig. 4 Level 1 from the Sega Genesis game, Sonic and Knuckles, reproduced from http://www.gamefabrique.com/screenshots/sonic-and-knuckles/ (Accessed on April 15, 2014) 


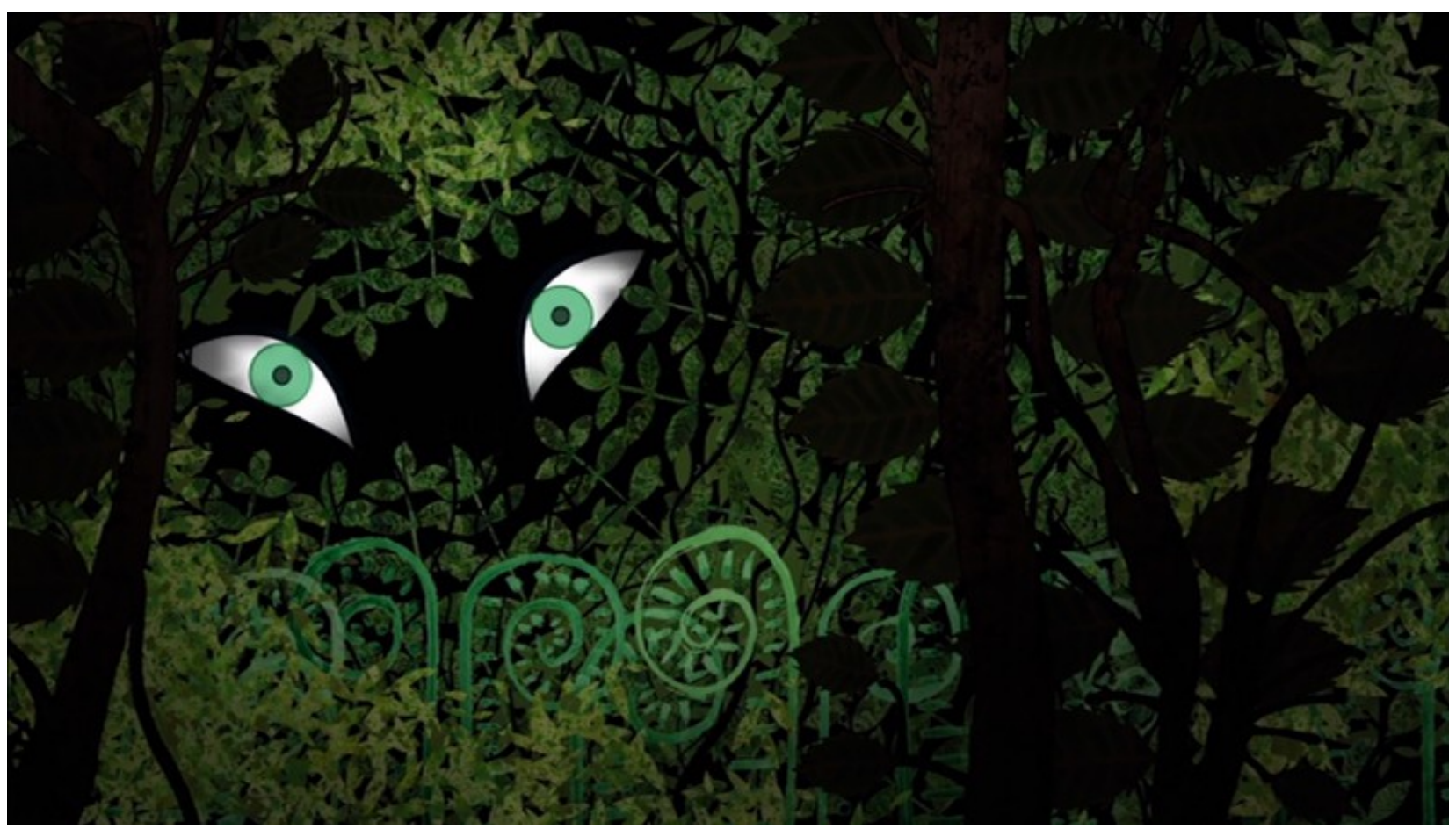

Fig. 5 Tomm Moore, The Secret of Kells (screen shot), 2008. Reproduced from: The Secret of Kells. DVD. New Video Group, Inc, 2010. 


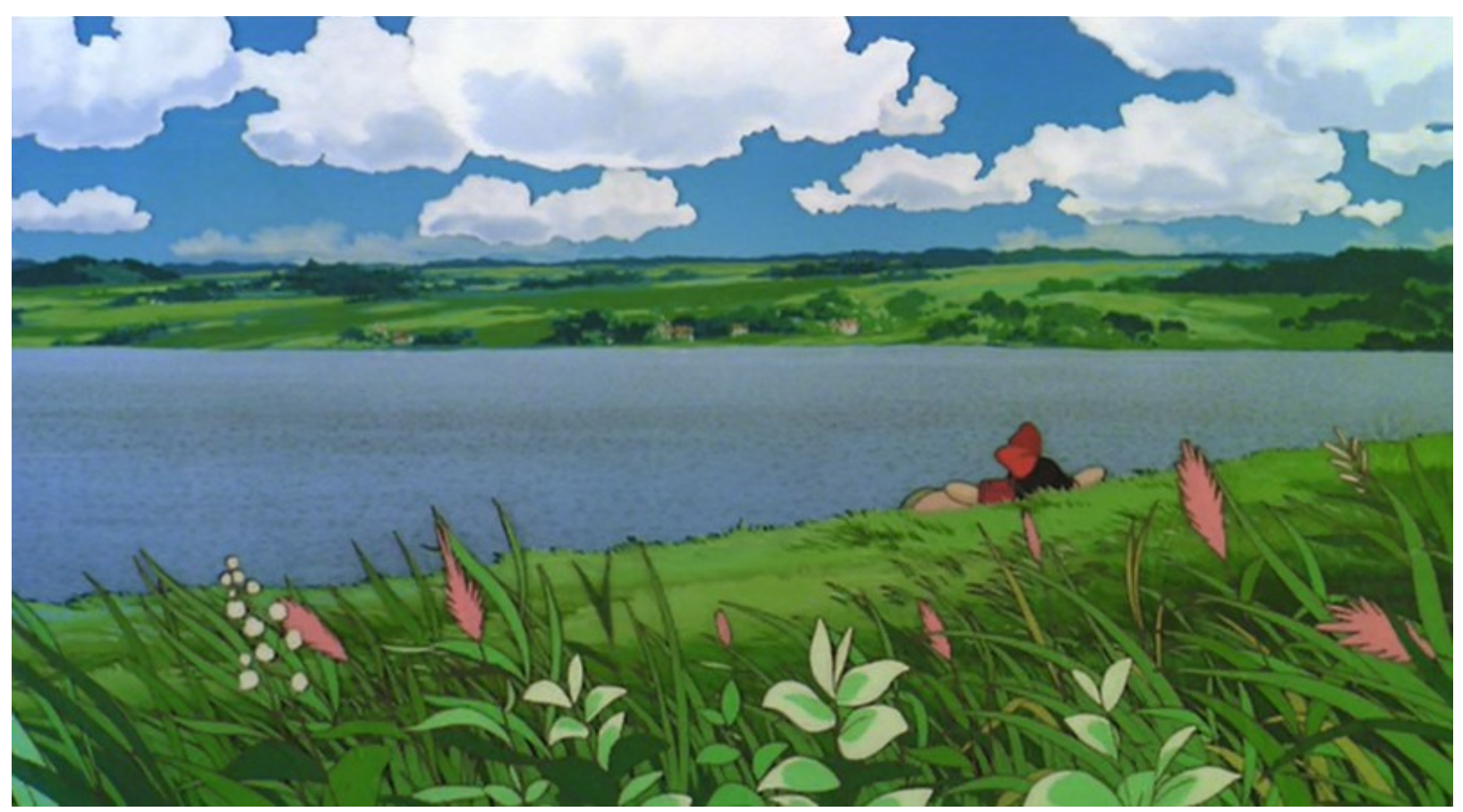

Fig. 6 Hayao Miyazaki, Kiki's Delivery Service (screen shot), 1989. Reproduced from Kiki's Delivery Service. DVD. Burbank, CA: Buena Vista Home Entertainment, 2003. 


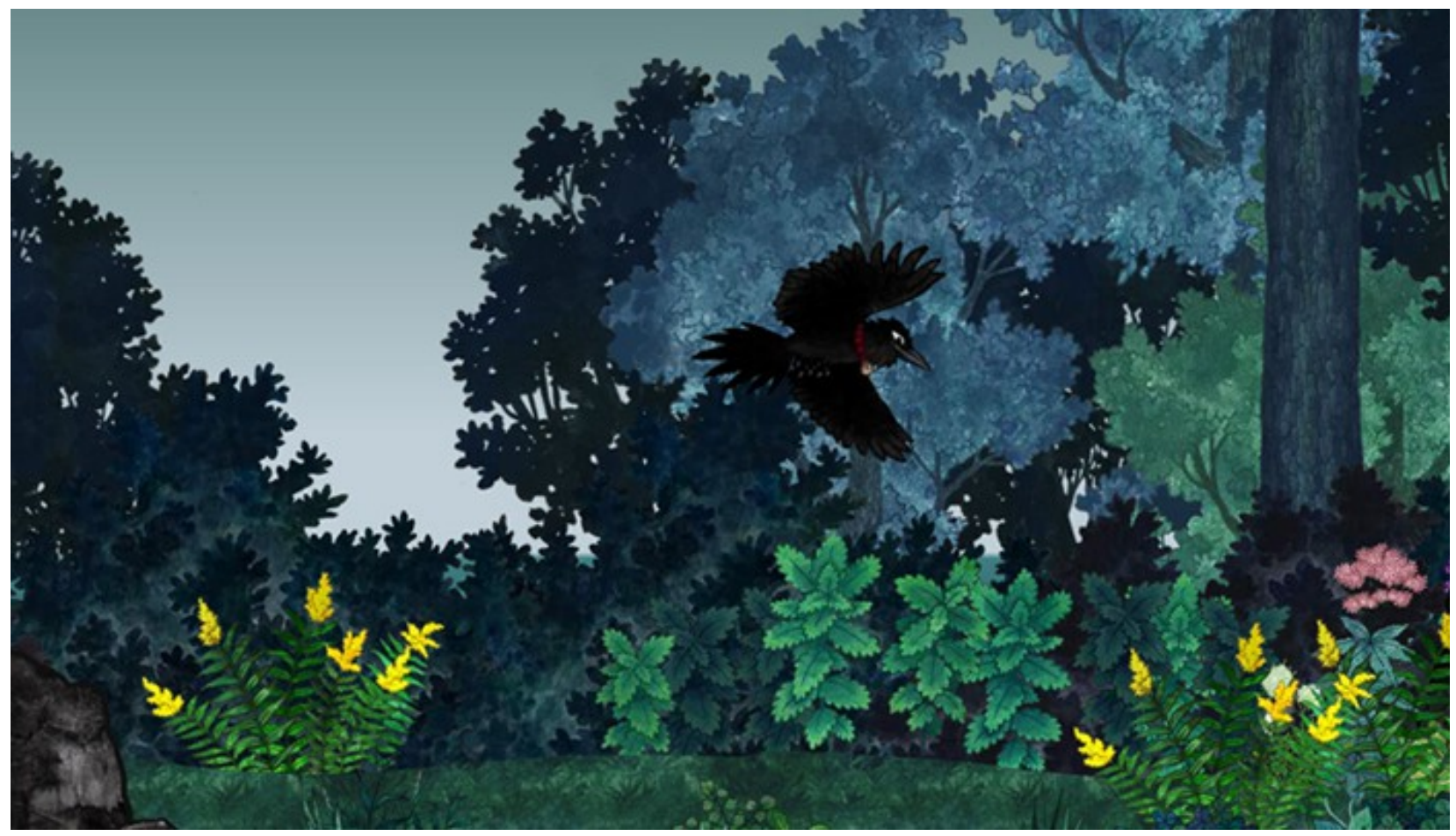

Fig. 7 Kristine R Synowka, The Experience of Flight (screen shot), 2014. Digital interactive animation. 


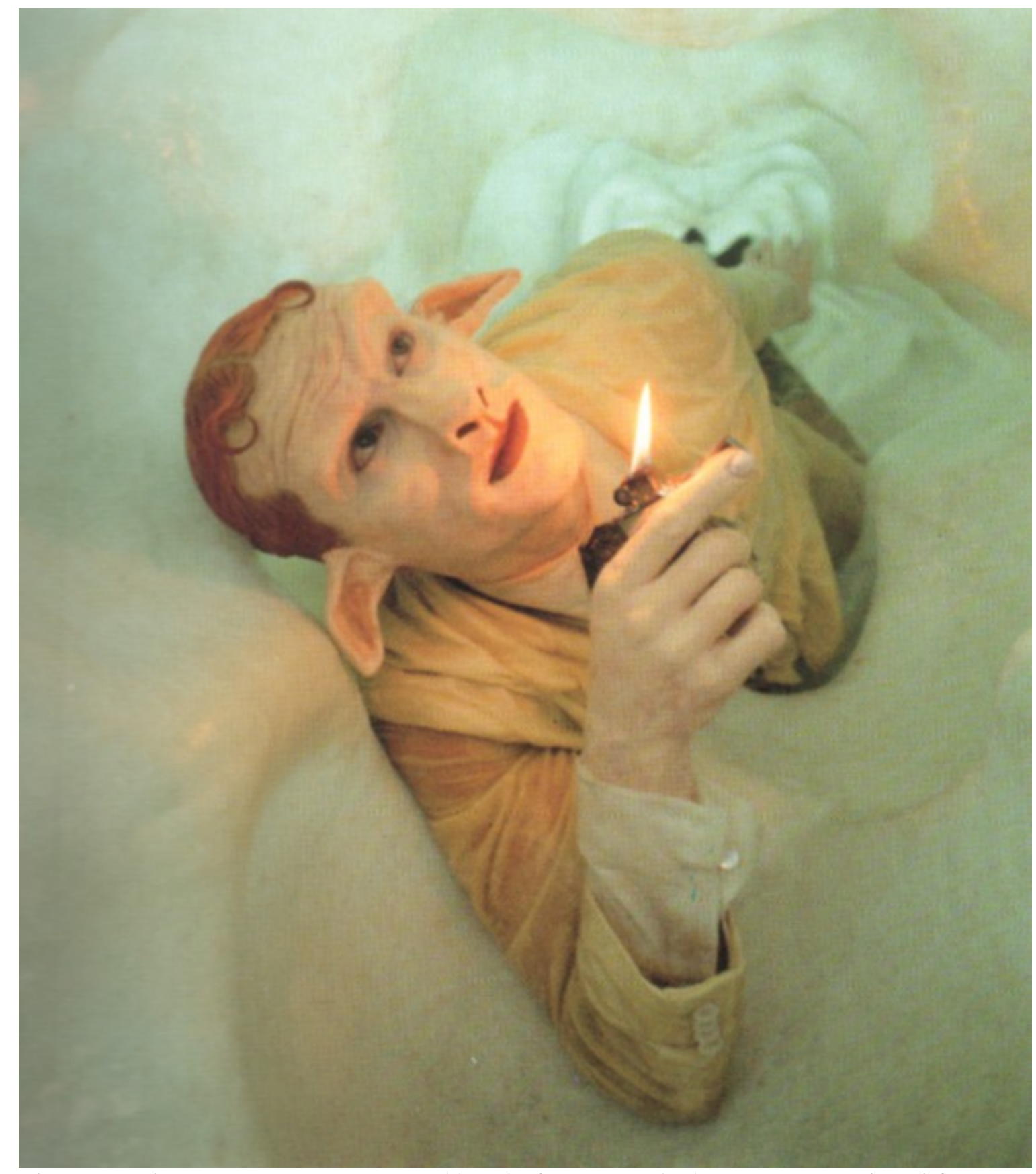

Fig. 8 Matthew Barney, Cremaster4 (detail of a screen shot), 1994. Reproduced from: Cremaster 4. New York: Barbara Gladstone Gallery, 1995. 


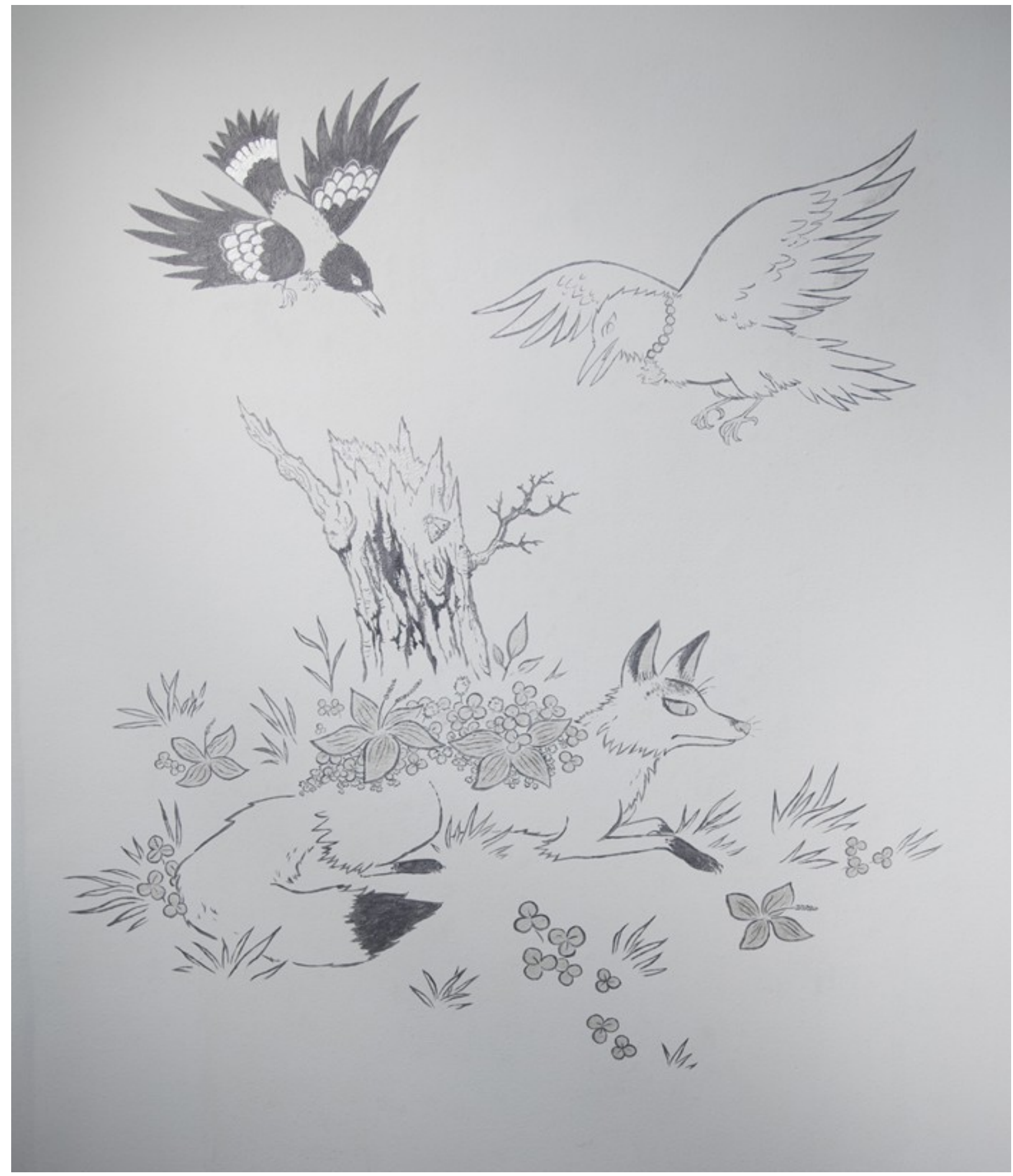

Fig. 9 Kristine R. Synowka, Untitled, 2014. Acrylic paint on wall. 


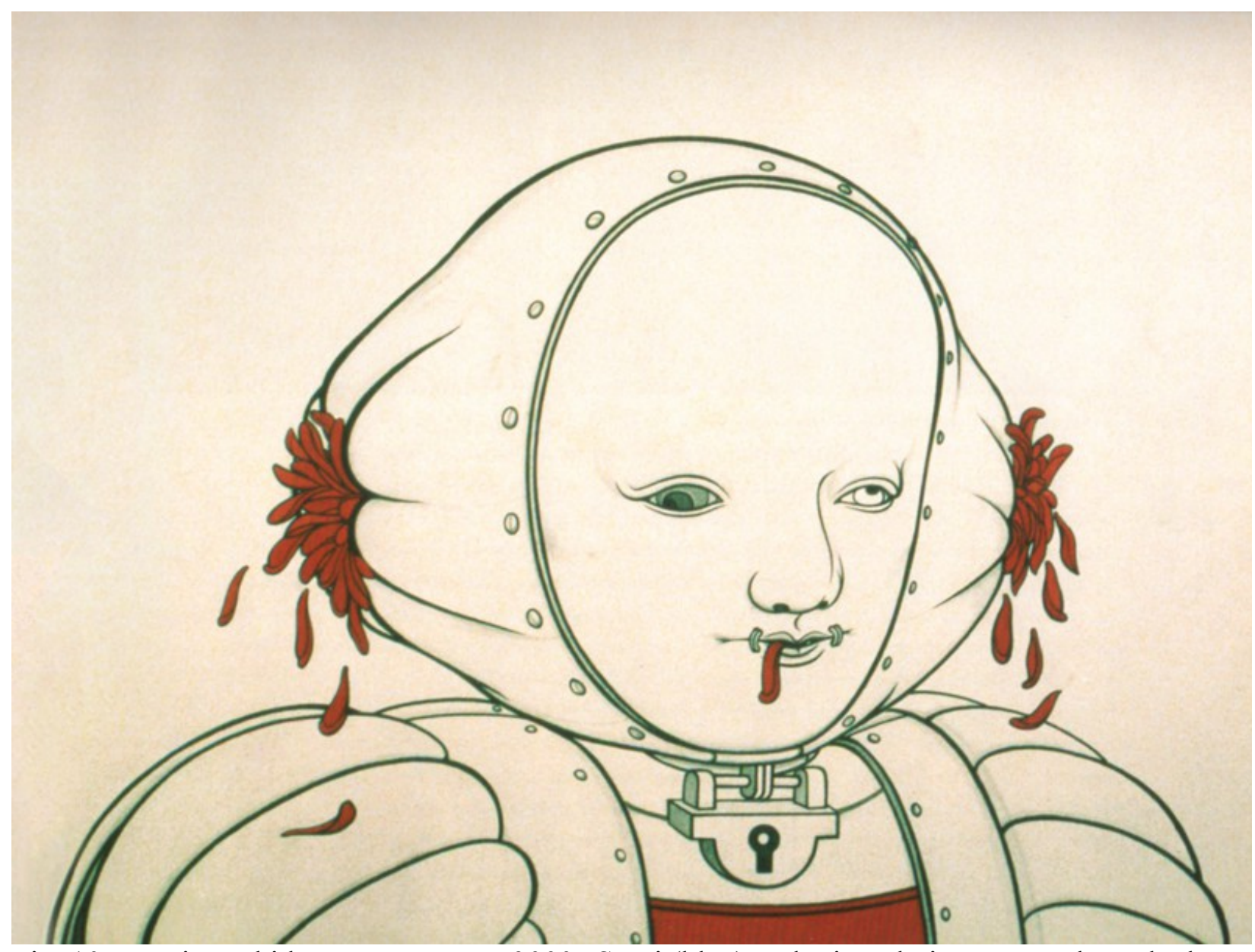

Fig. 10 Kumi Machida, La Degrange, 2003. Sumi (blue) and mineral pigments on kumohada linen paper, $115 / 8 \times 16 \frac{1}{2}$ on. Private collection. Reproduced from Bye Bye Kitty: Beyond Heaven and Hell in Contemporary Japanese Art. New York: Japan Society, 2011. Fig. 24. 


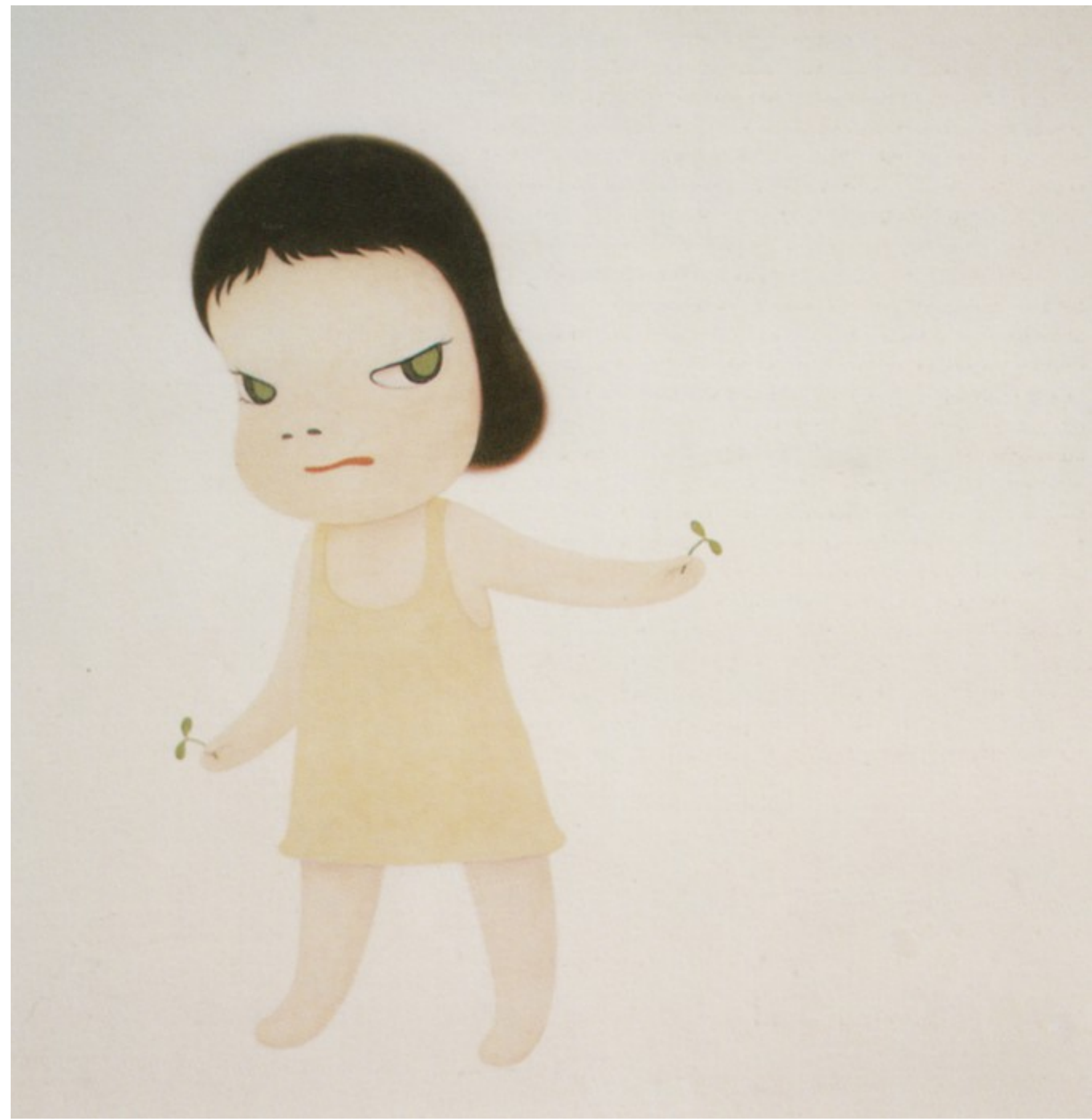

Fig. 11 Yoshitomo Nara, Sprout the Ambassador, 2001. Acrylic on canvas. 84 x 72 in. Reproduced from: Vitamin P. London: Phaidon Press Limited, 2002. 


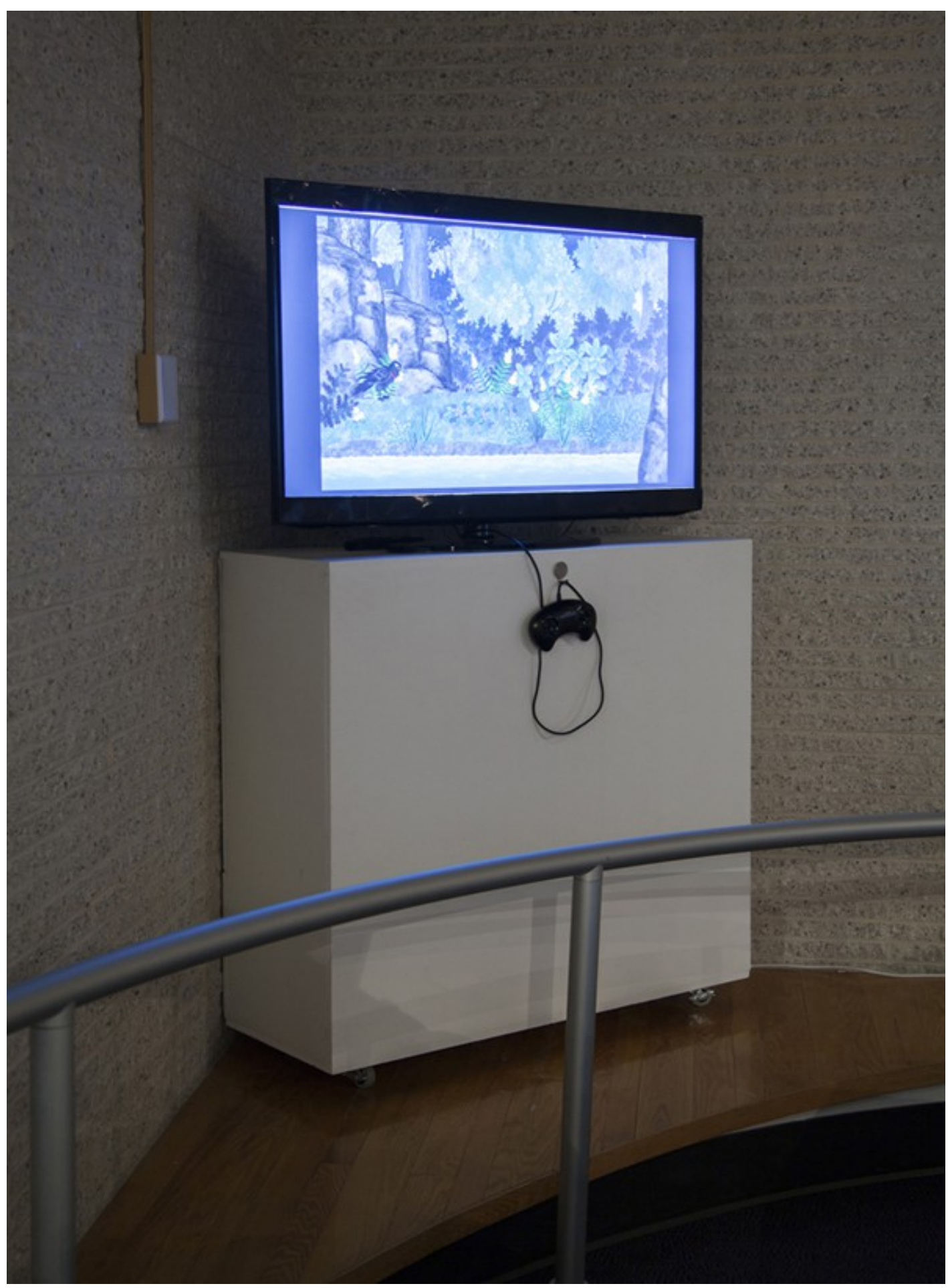

Fig. 12 Kristine R. Synowka, The Experience of Flight (set up), 2014. Digital interactive animation. 


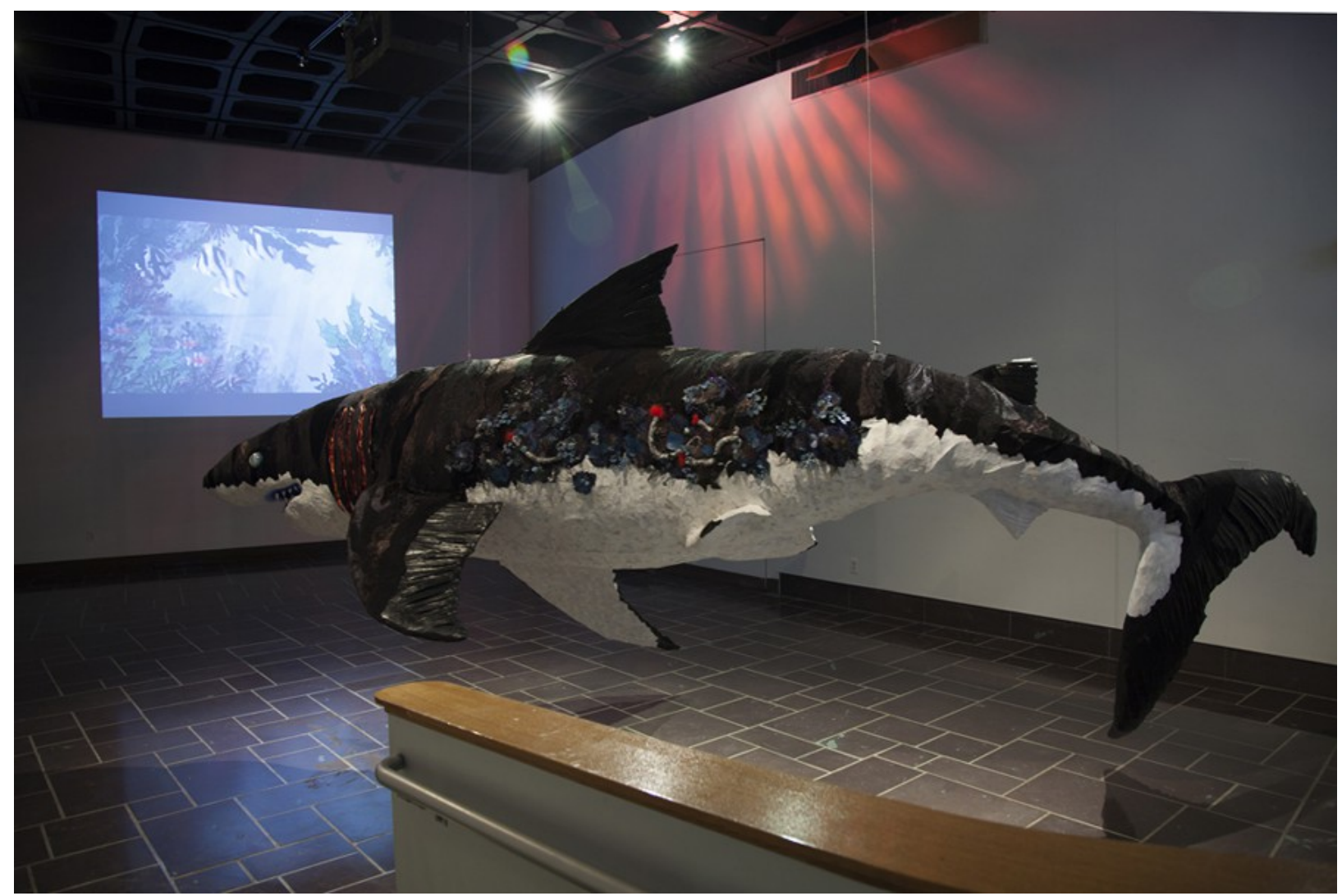

Fig. 13 Kristine R. Synowka, Untitled, 2014. Paper mache, fabric, decorative paper, plastic plants, feathers, and other mixed media. 


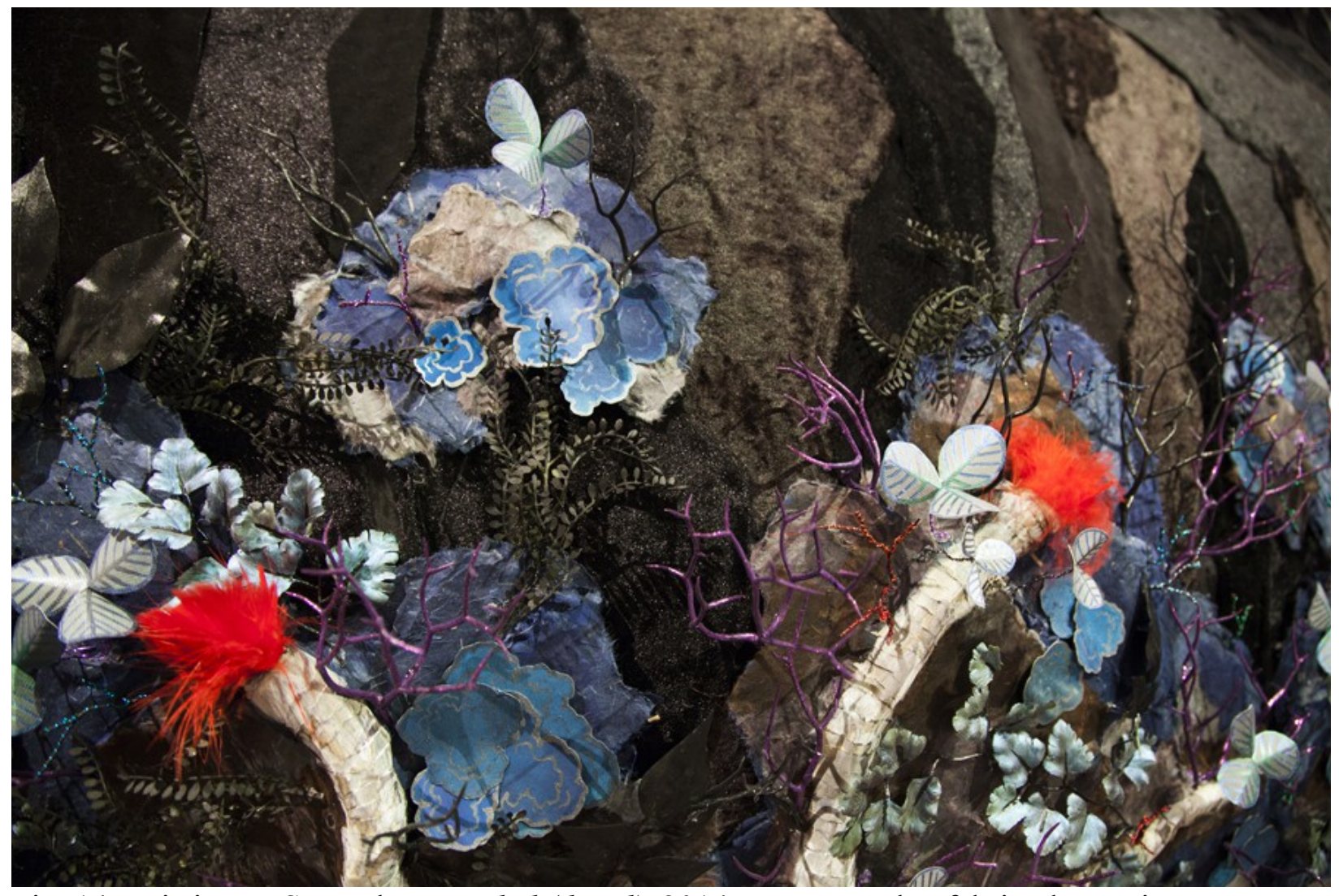

Fig. 14 Kristine R. Synowka, Untitled (detail), 2014. Paper mache, fabric, decorative paper, plastic plants, feathers, and other mixed media. 


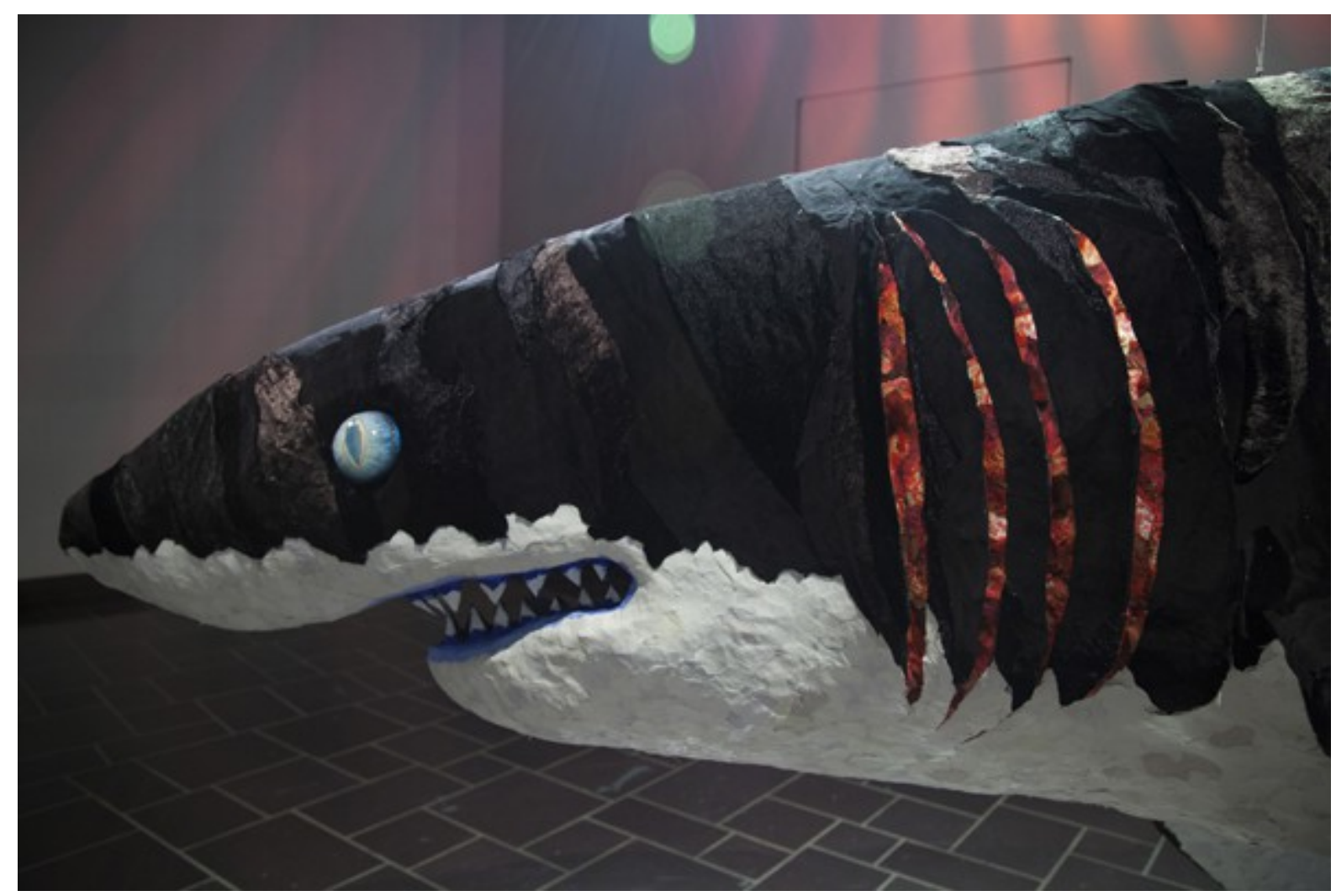

Fig. 15 Kristine R. Synowka, Untitled (detail), 2014. Paper mache, fabric, decorative paper, plastic plants, feathers, and other mixed media. 


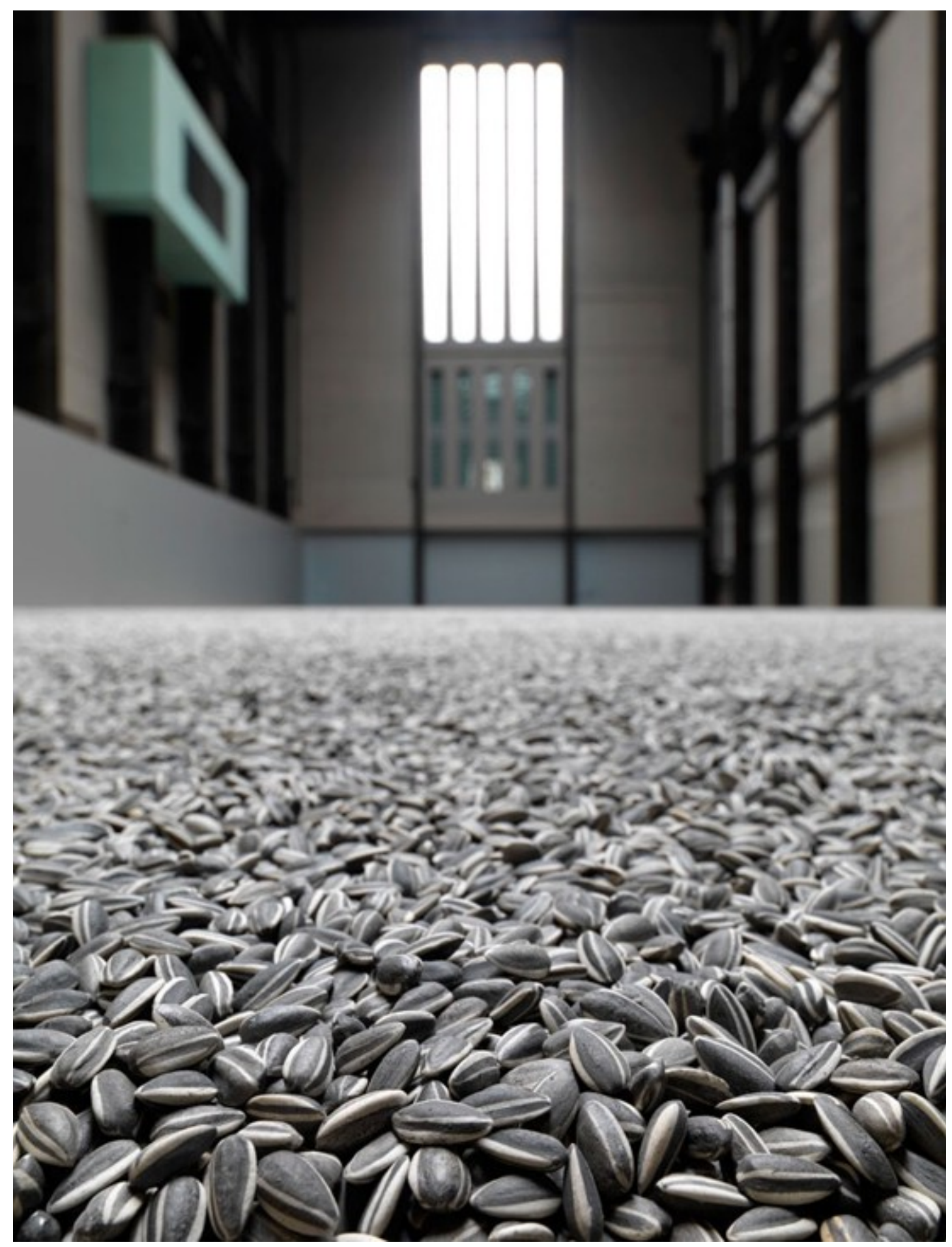

Fig. 16 Ai Weiwei, Sunflower Seeds, 2010. Porcelain. Reproduced from: The Tate Modern, http:/www.tate.org.uk/whats-on/tate-modern/exhibition/unilever-series-aiweiwei-sunflower-seeds (April 24, 2014). 


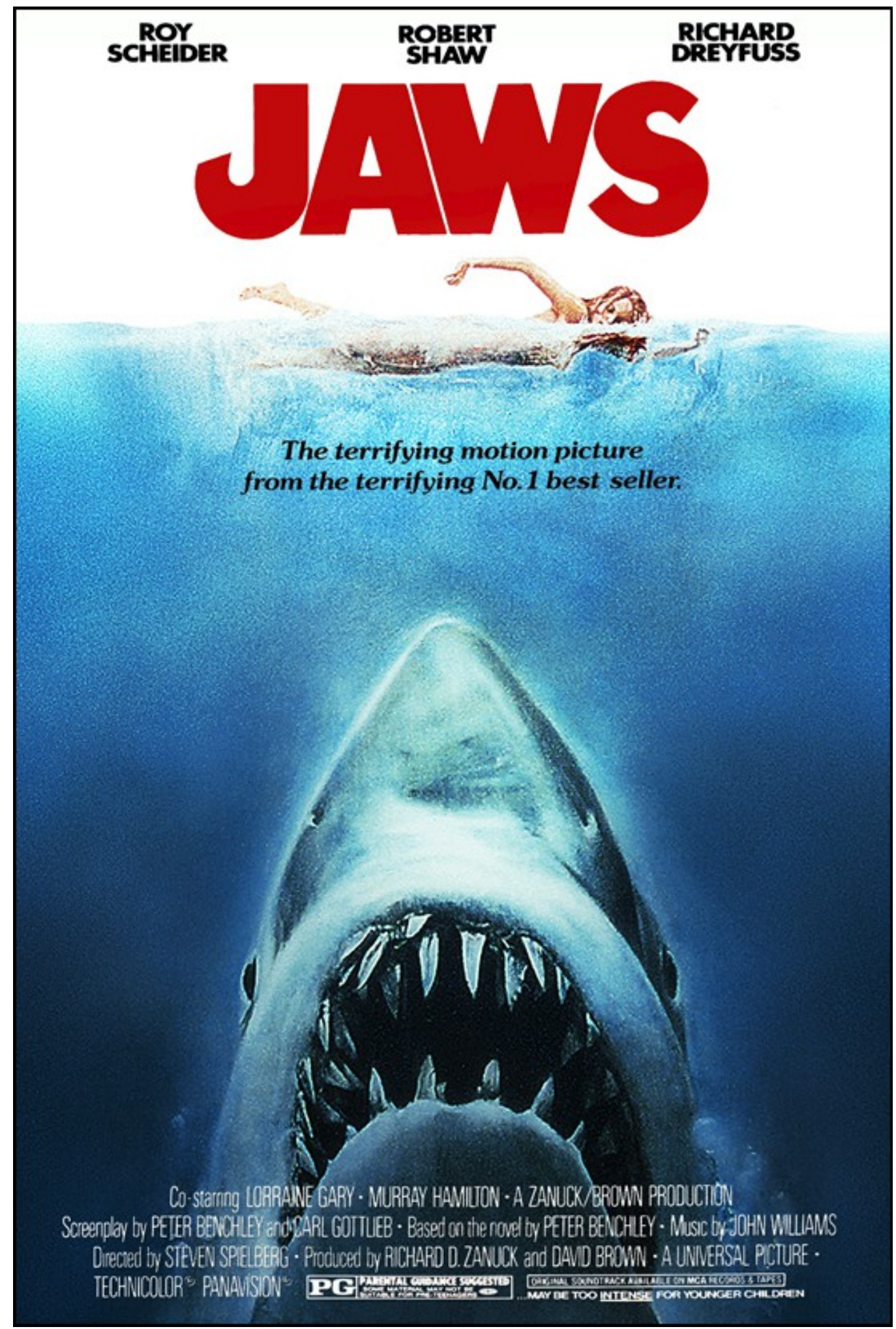

Fig. 17 Poster for the 1975 movie, Jaws. Reproduced from:

http://flickfacts.com/movie/67/jaws (Accessed on April 26, 2014). 


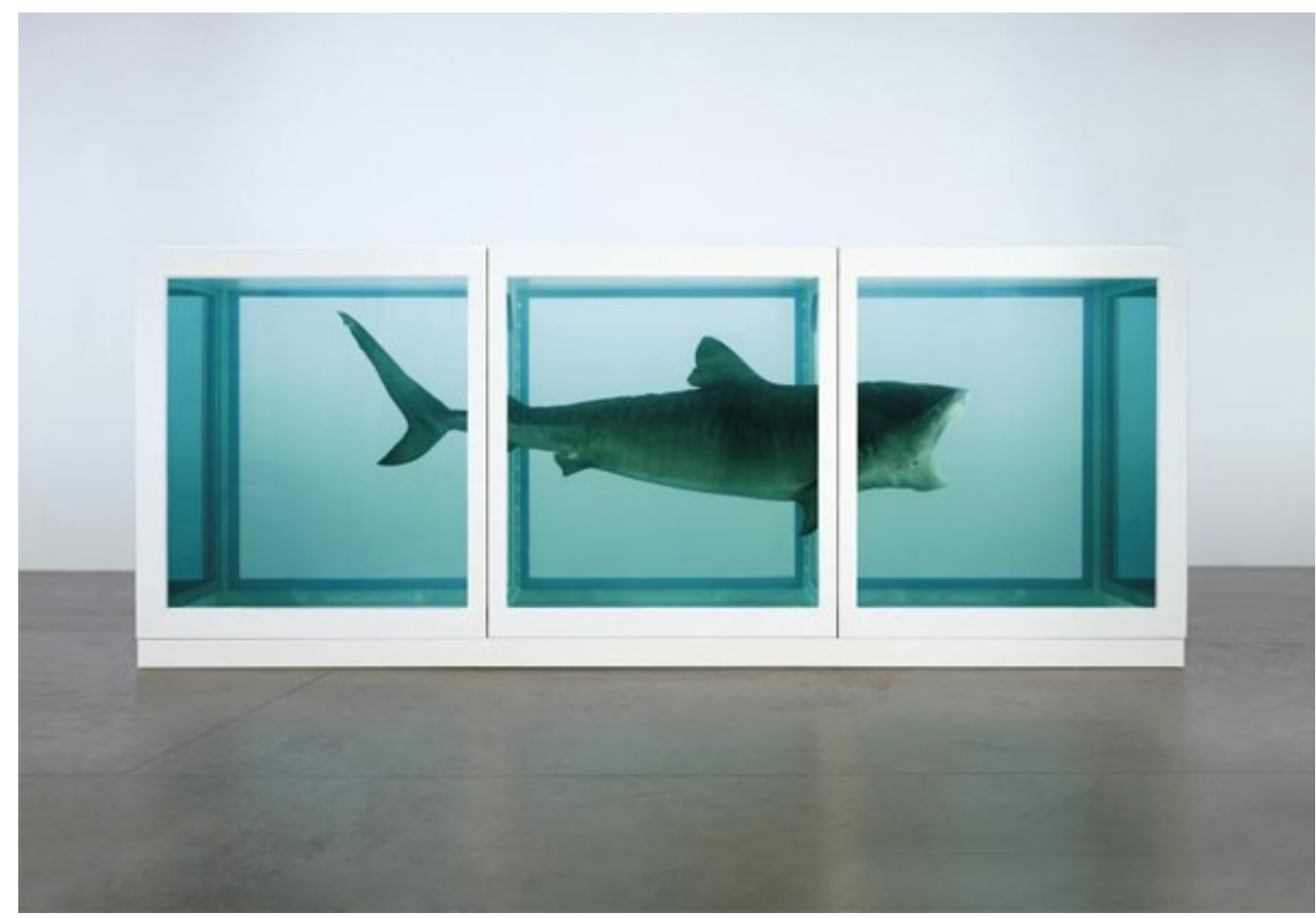

Fig. 18 Damien Hirst, The Physical Impossibility of Death in the Mind of Someone Living, 1991. Glass, painted steel, silicone, monofilament, shark and formaldehyde solution.

Reproduced from: http://www.damienhirst.com/the-physical-impossibility-of (Accessed on April 26, 2014). 


\section{Bibliography}

Breuvart, Valerie, ed. Vitamin P. London: Phaidon Press Limited, 2002.

Campbell, Joseph. The Hero with a Thousand Faces. 2nd ed. Princeton: Princeton University Press, 1949.

Campbell, Joseph, with Bill Moyers. The Power of Myth. Edited by Betty Sue Flowers. New York: Doubleday, a Division of Bantam Doubleday Dell Publishing Group, 1988.

Barney, Matthew. Cremaster 4. New York: Barbara Gladstone Gallery, 1995.

Elliot, David and Tetsuya Ozaki. Bye Bye Kitty: Beyond Heaven and Hell in Contemporary Japanese Art. New York: Japan Society, 2011.

Ferrari Andrea and Antonella Ferrari. Sharks: A Firefly Guide. 1st ed. Buffalo, NY: Firefly Books, 2002.

Gaiman, Neil. Anansi Boys. New York: Harper Torch, an Imprint of HarperCollins Publishers, 2005.

Gaiman, Neil. Neverwhere. New York: Harper Perennial, an Imprint of HarperCollins Publishers, 1996.

“Jaws (1975).” Flick Facts, http://flickfacts.com/movie/67/jaws (accessed April 26, 2014).

King, Gabriel. The Wild Road. New York: Del Rey, an Imprint of Ballantine Publishing Group, 1997.

Lewis, Ben. "Matthew Barney." Art Safari. DVD. Directed by Ben Lewis. 2002-05. Icarus Films Home Video, 2009.

Low, Phillip. "Cambridge Declaration of Consciousness." Edited by Jaak Panksepp et al. Paper 
presented at the Francis Crick Memorial Conference on Consciousness in Human and non-Human Animals, Cambridge, UK, July 7, 2012.

http://fcmconference.org/img/CambridgeDeclarationOnConsciousness.pdf (accessed April 23, 2014).

"The Physical Impossibility of Death in the Mind of Someone Living, 1991." Damien Hirst, http://www.damienhirst.com/the-physical-impossibility-of (accessed April 26, 2014).

Marzluff, John M. and Tony Angell. In the Company of Crows and Ravens. New Haven, CT: Yale University Press, 2005.

Miyazaki, Hayao. Kiki's Delivery Service. DVD. Directed by Hayao Miyazaki. 1989. Burbank, CA: Buena Vista Home Entertainment, 2003.

Moore, Tomm. The Secret of Kells. DVD. Directed by Tomm Moore, Nora Twomey. 2008. New Video Group, Inc, 2010.

"Sega Genesis." TV Tropes Foundation, http://tvtropes.org/pmwiki/pmwiki.php/Main/SegaGenesis (accessed April 13, 2014).

Shetty, Priya. "Novels act like social glue, say literary Darwinists." New Scientist 201, no. 2691 (January 17, 2009): 10. Academic Search Alumni Edition, EBSCOhost (accessed April 12, 2014).

"Sonic and Knuckles Screenshots." GameFabrique, http://www.gamefabrique.com/screenshots/sonic-and-knuckles/ (accessed April 12, 2014).

"The Unilever Series: Ai Weiwei: Sunflower Seeds." Tate, http://www.tate.org.uk/whats-on/tatemodern/exhibition/unilever-series-ai-weiwei-sunflower-seeds (accessed April 24, 2014).

Viegas, Jennifer. "Cats Have Super, Psychedelic Vision.” Discovery Communications, LLC. Last modified February 18, 2014. http://news.discovery.com/animals/pets/cats-havesuper-psychedelic-vision-140218.htm (accessed April 22, 2014).

Wolf, Mark J. P. “Assessing Interactivity in Video Game Design.” In Mechademia 1: Emerging 
Worlds of Anime and Manga, edited by Frenchy Lunning, 78-85. Minneapolis, University of Minnesota Press, 2006.

Yamaguchi, Yumi. Warriors of Art. Translated by Arthur Tanaka. Tokyo: Kodansha International, 2007. 